\title{
CHARACTERIZATION OF THE EQUINE SPERMADHESIN HSP-7 FOUND ON STALLION SPERMATOZOA AS IT RELATES TO STALLION FERTILITY AND SPERM CAPACITATION
}

\author{
A Thesis \\ Presented to \\ the Faculty of California Polytechnic State University, \\ San Luis Obispo
}

\author{
In Partial Fulfillment \\ of the Requirements for the Degree \\ Master of Science in Agriculture with a Specialization in Animal Science
}

by

Melodee Kathleen Heidmiller

July 2009 
(C) 2010

Melodee Kathleen Heidmiller

ALL RIGHTS RESERVED 


\section{COMMITTEE MEMBERSHIP}

TITLE: Characterization of the Equine Spermadhesin HSP-7 Found on

Stallion Spermatozoa as it Relates to Stallion Fertility and Sperm Capacitation

AUTHOR: Melodee Kathleen Heidmiller

DATE SUBMITTED: March 2011

COMMITTEE CHAIR: William E. Plummer, Ph.D., Reproductive Physiologist, California Polytechnic State University, CA

COMMITTEE MEMBER: P.L. Senger, Ph.D., Current Conceptions Inc., Pullman, WA

COMMITTEE MEMBER: Daniel G. Peterson, Ph. D., Molecular Physiology and Genomics Specialist, California Polytechnic State University, CA

COMMITTEE MEMBER: Matthew A. Burd, M.S., D.V.M., Equine Reproductive Physiologist, California Polytechnic State University, CA 


\begin{abstract}
Characterization of the Equine Spermadhesin HSP-7 Found on Stallion Spermatozoa as it Relates to Stallion Fertility and Sperm Capacitation

Melodee Kathleen Heidmiller
\end{abstract}

Equine spermadhesin HSP-7 is a $14 \mathrm{kDa}$ protein isolated from stallion seminal plasma and present on the surface of spermatozoa. HSP-7 displays carbohydrate and zona-pellucida binding properties, but the physiological role in equine fertilization is not well defined. HSP-7 has $98 \%$ amino acid sequence homology with the well-studied boar spermadhesin, AWN. Currently, these two proteins are considered to have the same reproductive function. Immunofluorescence studies presented here show that the stallion and boar spermadhesins are localized to different segments on spermatozoa. The variation in molecular compartmentalization of spermadhesin molecules in different species suggests that these structurally related proteins could be involved in independent events of fertilization. While the variation in HSP-7 abundance was not statistically significant between fertile and subfertile stallions, capacitated spermatozoa displayed a marked increase in HSP-7 when compared to neat sperm $(P<0.05)$. These results indicate that rather than aiding in capacitation, HSP-7 is exposed with capacitation and may have a more significant role in the acrosome reaction and sperm-oocyte recognition than previously documented. 
Keywords: Equine; spermadhesin; seminal plasma protein; HSP-7;

capacitation 


\section{CHAPTERS}

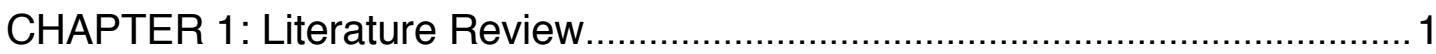

\section{CHAPTER 2:}

PART 1: Introduction

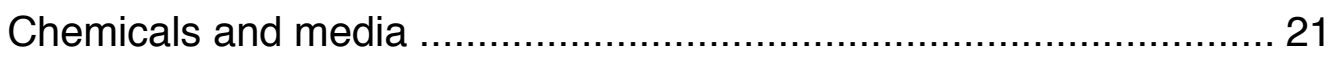

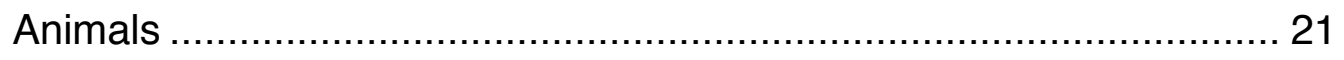

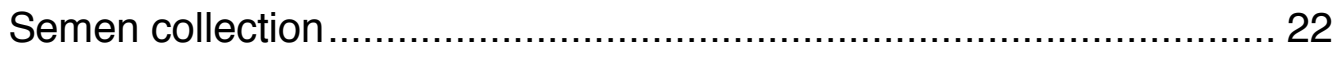

Sperm processing for percoll centrifugation and in vitro capacitation .. 23

Sperm processing for in vitro acrosome reaction............................... 24

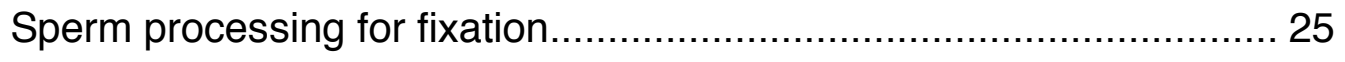

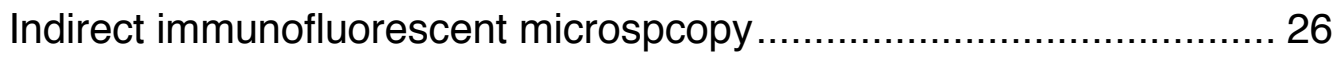

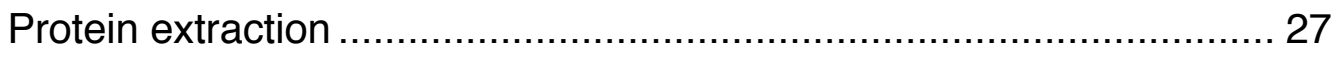


Western blotting

Equine transvaginal follicular aspiration 29

Bovine oocyte collection. 30

Bovine and equine oocyte vitrification and thaw 31

Sperm-oocyte binding, fixation and immunofluorescence 32

Statistical analysis 33

PART 3: Results 34

Validation of HSP-7 antibody 34

Indirect immunfluorescent microscopy 35

In vitro capacitation 38

Immunofluorescence of capacitated and acrosome reacted spermatozoa. 39

Western blot analysis 40

Equine transvaginal ultrasound-guided follicular aspiration. .43

Vitrification of bovine and equine oocytes 43

Sperm-oocyte binding, fixation and immunofluorescence 44

PART 4: Discussion. 46 


\section{APPENDICES}

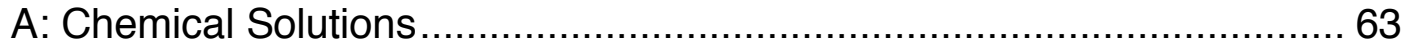

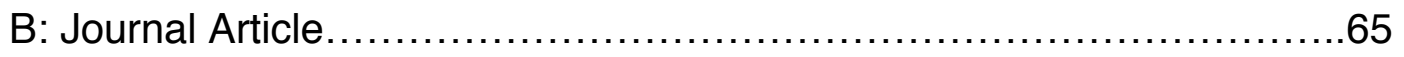

Images and Captions............................................... 83

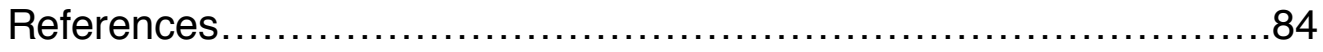




\section{LIST OF FIGURES}

Page

1. Depiction of the structural components of spermatozoa ........................... 2

2. Proposed model of porcine AWN ..................................................... 7

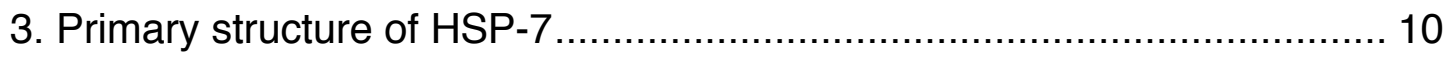

4. Negative control for anti-AWN antibody ............................................... 36

5. HSP-7 labeling of neat spermatozoa during the breeding

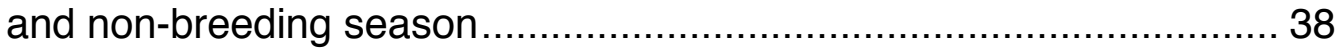

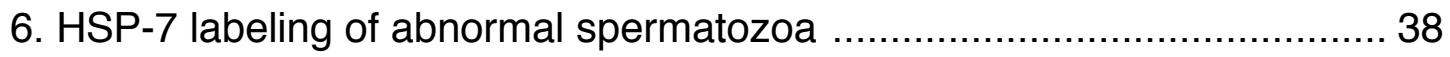

7. Variation of protein abundance within an ejaculate ................................ 39

8. Absence of HSP-7 labeling on neat spermatozoa ................................... 39

9. HSP-7 labeling of ethanol permeabilized spermatozoa .......................... 40

10. Localization of HSP-7 on the capitulum of spermatozoa ...................... 40

11. Differential immunofluorescence: acrosome reacted

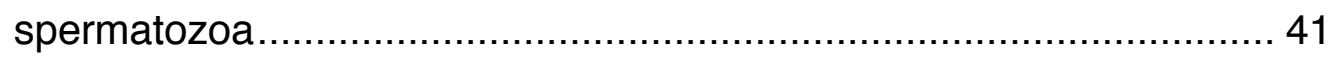

12. Rate of capacitation based on acrosome reaction ............................... 41

13. Immunofluorescence of capacitated spermatozoa ............................... 42

14. Western blot: total sperm protein and seminal 
plasma protein

15. Western blot: total sperm protein of fertile and

subfertile stallions

16. Western blot: variation of HSP-7 abundance between

December, March and May 45

17. Western blot: variation of HSP-7 abundance between

breeding and non-breeding season. 45

18. Western blot: post capacitation 46

19. Depiction of follicular aspiration 47

20. Sperm oocyte binding 49

21. Bovine oocyte immunofluorescence 49 


\section{CHAPTER ONE}

\section{LITERATURE REVIEW}

Mammalian spermatozoa are synthesized in the seminiferous epithelium and secreted into the lumen of the seminiferous tubules as functionally immature cells that are unable to fertilize an oocyte. Spermatozoa are highly differentiated haploid cells which transform into motile, functional cells during epididymal transit (Senger, 2005). The structure of spermatozoa consists of a head, neck, middle piece and principal piece (Figure 1). The head of spermatozoa includes the nucleus, acrosome and post-acrosomal lamina, which are surrounded by a plasma membrane. The shape of the spermatozoal nucleus defines the shape of the sperm head and therefore, equine spermatozoa are broad and flat. The rostral portion of the sperm nucleus is covered by the acrosome, which is a double-layered membrane with enzymatic activity. During the initial stage of fertilization, the equatorial segment, which lies at the base of the acrosome, is the site of physical interaction between the spermatozoal plasma membrane and the zona pellucida. Upon fusion with the oocyte, the acrosome reaction allows for the spermatozoa to penetrate the zona pellucida and gain access to the perivitelline space (Ellis et al., 2002). The plasma membrane is the outermost

component surrounding a spermatozoon and consists of three distinct zones: lipid bilayer, phospholipid-water interface and glycocalyx. Integral and peripheral proteins are intermingled into the lipid bilayer with a negative net 
charge, attracting and loosely binding proteins from the seminal plasma (McKinnon and Voss, 1992).

The midpiece region of spermatozoa contains a high concentration of organelles with abundant mitochondria, producing ATP for cell metabolism and flagellar movement. The principle piece is composed of myofibrils that allow spermatozoa to propel through the female reproductive tract with wavelike and whip-like movements to (Morel, 1999).

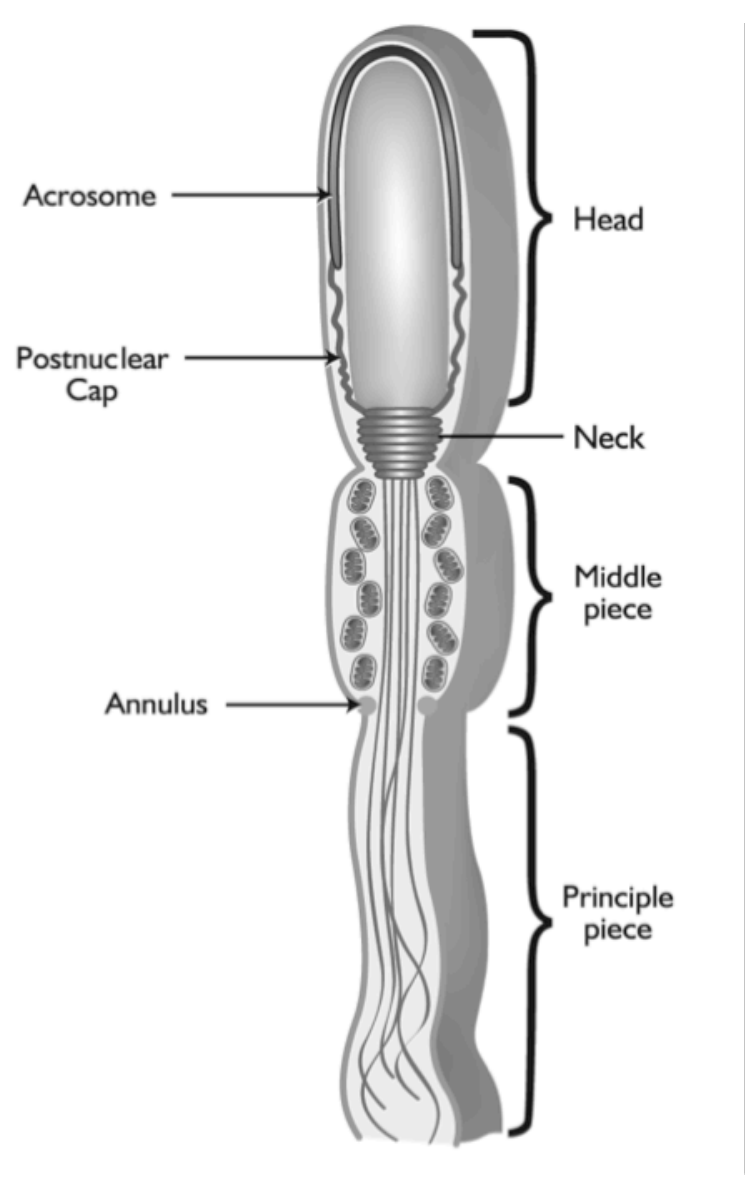

Figure 1. Depiction of the structural components of spermatozoa. (Courtesy of Senger, 2005) 
Seminal plasma is the non-cellular, liquid portion of semen produced from the epididymis and accessory sex glands (ampulla, seminal vesicles, prostate and bulbourethral glands) (Senger, 2005). During epididymal transit, spermatozoa are transported from the proximal head (caput), through the body (corpus) and to the distal tail (cauda) of the epididymis. The head of the epididymis receives spermatozoa via several efferent ducts from the testicular mediastinum. As the ducts continue towards the tail of the epididymis, they eventually merge and form a single duct called the ductus deferens (McKinnon and Voss, 1992). During epididymal transit, spermatozoa are surrounded by seminal plasma which includes, but is not limited to; sperm associated proteins, hormones, enzymes, protease inhibitors and other components such as growth factors and glycoproteins (Topfer-Petersen et al., 2005). Some of the major constituents include organic solutes and ions such as sodium, potassium, chloride and bicarbonate (Hinton, 2005). Over 200 proteins are represented within the seminal plasma (Senger, 2005) that adhere to the plasma membrane creating a protein coat that is involved in the stabilization of the plasma membrane and assists in the acquisition of fertility (Kirchhoff, 1998; Reinert et al., 1996). These proteins represent more than $50 \%$ of the weight of the plasma membrane (McKinnon and Voss, 1992). The exact role of each component in the maturation of spermatozoa is unknown, but several studies suggest they assist in spermatozoal motility, cellular metabolism, maturation, capacitation and zona pellucida binding. In addition, 
seminal plasma is a hyperosmotic solution with an approximate $\mathrm{pH}$ of 6.8 that serves as an osmoregulator for spermatozoa and epididymal epithelial cells (Hinton, 2005).

In equid seminal plasma, three protein classifications have been identified which are involved in fertilization: fibronectin type II proteins (Fn-2), cysteine-rich secretory proteins (CRISP) and spermadhesins. Fibronectin type II proteins contain two tandemly arranged fibronectin type two modules. They interact with phospholipids such as choline lipids on the sperm membrane and exhibit heparin-binding properties. They are the most abundant protein class within an equine ejaculate, but do not appear to directly assist in fertility. Cysteine-rich secretory proteins are characterized by 16 conserved cysteine residues and a two-domain structure. The function of CRISP proteins is unknown in the equine specie but in the rat, CRISP proteins bind to the spermatozoal plasma membrane and participate in sperm-oocyte binding (Topfer-Petersen et al., 2005). However, CRISP proteins lack the ability to activate the oocyte and undergo the acrosome reaction (Ekhlasi-Hundrieser et al., 2005, Topfer-Petersen et al., 2005). The final classification of proteins is termed spermadhesins, appropriately named for their multifunctional characteristics of ligand-binding properties to heparin and carbohydrates, along with protease inhibition (Topfer-Petersen et al., 2005).

Within the classifications of Fn-2 type proteins, CRISP and spermadhesins, eight major proteins have been classified: horse seminal 
protein (HSP) HSP-1 through HSP-8. These proteins range from 14 to $30 \mathrm{kDa}$ in size (Calvete et al., 1994a). Horse seminal protein one and two (both Fn-2 type proteins) are the most abundant proteins isolated from equine seminal plasma, accounting for $70-80 \%$ of the total protein (Calvete et al., 1995a). Horse seminal protein three is a member of the CRISP family, ubiquitously found in mammals yet it is not restricted to the male reproductive tract. Horse seminal protein three possesses high amino acid sequence similarity to a major rat sperm surface glycoprotein, which participates in sperm-oocyte binding. The specific role of HSP-3 in equine sperm-oocyte binding has yet to be determined. Horse seminal protein four is related to a calcitonin gene-like product and is a participant in sperm motility and prevents premature capacitation and the acrosome reaction. The role of HSP-5 has not been related to any known proteins and its role has yet to be determined. Horse seminal proteins six and eight are different isoforms of a protein belonging to the kallikrein-like protein family and are involved in the cleavage of the seminal coagulum (Topfer-Petersen et al., 2005). Finally, HSP-7 is a spermadhesin protein containing one or more heparin binding sites and is hypothesized to aid in sperm-oocyte binding and capacitation due to its molecular architecture and localization on neat spermatozoa (Calvete et al., 1994a).

Spermatozoal associated lectins of low molecular weight (12 to $30 \mathrm{kDa}$ ) are titled spermadhesins and have emerged over the last decade. These 
proteins not only display significant zona pellucida binding properties but they may also contribute to sperm capacitation. Spermadhesin molecules range from 110-133 amino acids and are stabilized by a single CUB domain (complement subcomponents Clr and Cls) with two conserved disulfide bridges with neighboring cysteine residues (Bork and Beckmann, 1993; Topfer-Petersen et al., 2005). Numerous spermadhesin molecules have been studied across species, including AWN/AWN-1 and AQN (named according to their first three $\mathrm{N}$-terminal amino acids) found in the boar, acidic seminal fluid protein (aSFP) in the bull and HSP-7 which is also termed seminal plasma protein seven (SSP-7) (Calvete et al., 1995b; Reinert et al., 1997).

Boar spermadhesins are the most studied spermadhesin molecule across species and have been identified as multifunctional proteins, displaying serine protease inhibition with zona pellucida glycoprotein and heparin binding properties. Boar spermadhesins are major secretory products of the seminal vesicles, rete testis and tubuli recti (Dostalova et al., 1994b). AWN is a $14 \mathrm{kDa}$ protein (Dostalova et al., 1995) consisting of 133 polypeptide residues (Reinert et al., 1996). The concentration of AWN within seminal plasma varies from 0.6 to $7.2 \mathrm{ug} / \mathrm{ml}$ (Sanz et al., 1992a) while total seminal plasma protein concentration ranges from $28-30 \mathrm{mg} / \mathrm{ml}$ (Dostalova et al., 1994b). The primary role of porcine spermadhesins is to aid in sperm capacitation (Calvete et al., 1997). Research has not identified the human homolog to AWN, but current research is directed toward the heparin binding 
protein fractions 9 and 11, where many spermadhesin molecules have been isolated (Kraus et al., 2005). Epididymal sperm are coated with an average of $7 \times 10^{6}$ AWN molecules per cell and upon ejaculation, an average of $12-60 \times$ $10^{6} \mathrm{AWN}$ molecules cover the acrosomal cap several molecules thick (Dostalova et al., 1994b and 1995). The significant increase in AWN abundance is due to AWN synthesis and secretion by the seminal vesicle epithelium (Hoshiba and Sinowatz, 1998) which peripherally attaches to the apical third of the acrosomal cap (Dostalova et al., 1995; EnBlin et al., 1995). AWN is thought to bind the spermatozoal surface through phosphorylethanolamine containing lipids on the external lipid bilayer (Figure 2; EnBlin et al., 1995). However, phosphorylethanolamine lipids are preferentially located on the inner leaflet of the lipid bilayer. Therefore, more research needs to be conducted to confirm that surface associated phosphorylethanolamine moieties are the functional group for AWN anchorage (EnBlin et al., 1995; Pommer et al., 2003). 


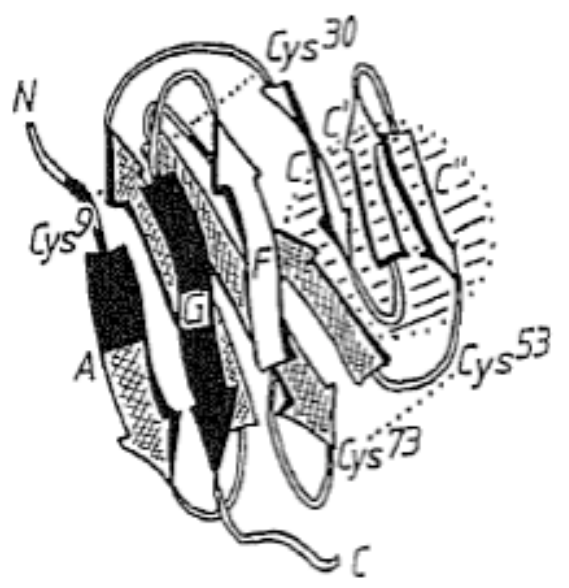

Figure 2. A proposed model of porcine AWN with relative locations of ligandbinding, carbohydrate-binding (shadowed circle) and the phosphorylethanolamine-binding regions (in black). Disulfide bridges are indicated with neighboring cysteine residues (cys). $\beta$-strands of the CUB module are $\mathrm{A}, \mathrm{G}, \mathrm{F}, \mathrm{C}, \mathrm{C}^{\prime}, \mathrm{C}^{\prime}$ with $\mathrm{N}$-terminus $(\mathrm{N})$ and $\mathrm{C}$-terminus (C). (From EnBlin et al., 1995)

Post in vitro capacitation, approximately $7 \times 10^{6} \mathrm{AWN}$ molecules remain attached to the spermatozoal surface (Dostalova et al., 1994b). It has been hypothesized that the variation in protein concentration between ejaculated and post capacitated spermatozoa is due to AWN stabilizing the acrosomal membrane prior to capacitation and aids in the event of capacitation. It is speculated that AWN molecules inhibit premature capacitation, protect zona pellucida binding sites that are exposed with capacitation and prevent a premature acrosome reaction (Dostalova et al., 1994b). These processes are thought to occur through heparin binding activity due to the affinity of AWN to acid polysaccharides (Dostalova et al., 1994; Tienthai et al., 2000). Not only is AWN thought to participate in capacitation, it has also been localized on spermatozoa bound to the zona pellucida of surgically collected oocytes 
(Ekhlasi-Hundrieser et al., 2005), purified zona pellucida (Dostalova et al., 1995) and attached to the epithelium of the uterotubal junction (UTJ) of inseminated sows (Calvete et al., 1997; Dostalova et al., 1995). In vitro, dose dependent incubation with purified AWN inhibits spermatozoa from binding zona pellucida encased oocytes (Sanz et al., 1992b).

AWN preferentially binds to $\beta$ galactoside specific lectin molecules via O-linked carbohydrate sequences on ooctyes via the common zona pellucida glycoproteins Gal $\beta 1-3 G a l N A c$ and Gal $\beta 1-4 G l c N A c$ (Dostalova et al., 1995). The ability of AWN to bind the oviductal epithelium may in part aid in the development of the oviductal reservoir of fertile spermatozoa (Calvete et al., 1997), which is the attachment of spermatozoa to the epithelium of the UTJ where they await a signal to be released and interact with the ovulated oocyte. In addition, AWN displays serine protease inhibition, which protects spermatozoa from undergoing proteolytic attack during maturation and transport through the female reproductive tract. Sanz and coworkers reported that serine protease inhibitors located on the acrosomal cap of spermatozoa also stabilize zona pellucida binding proteins (Sanz et al., 1992a). Some discrepancy has been observed concerning this role of $\mathrm{AWN}$, therefore further research is required to confirm this characteristic (Calvete et al., 1997;

Ekhlasi-Hundrieser et al., 2005; Rodriquez-Martinez et al., 1998).

While multiple spermadhesin molecules have been identified within the seminal plasma of the boar (AQN-1, AQN-3, AWN, PSP-1 and PSP-II), HSP-7 
is the only spermadhesin molecule identified within equine seminal plasma (Calvete et al., 1994a; Reinert et al., 1996; Topfer-Petersen et al., 2005). Only four studies to date have been conducted to identify the role of HSP-7 in equine reproduction and only a fraction of these studies have evaluated the similarities between AWN and HSP-7 (Calvete et al., 1994a). However, since boar AWN is the most studied spermadhesin molecule and has $98 \%$ sequence conservation with HSP-7, inference to the role of HSP-7 are made from AWN research (Figure 3; Calvete et al., 1994a).

\author{
A W NRRSRS C G GVLRDPPGKIFNSDGPQKDCVWTIK \\ VK P H F H V VLA I P PL N L S C G KE Y VE L L D G P P GS E II G K \\ IC G G IS LVFRS S S N I A T I KYLRT S GQR A S PFH I YYYA \\ DPE G PLPFPYFER QTIIATE KN IP
}

Figure 3. Primary structure of HSP-7. The amino acid structure of HSP-7 and boar AWN differ only in three amino acid residues (HSP-7/AWN: 144/L, Y92/R and $Q 98 / H$ ) which are underlined. (Courtesy of Reinert et al., 1996)

Localization studies of HSP-7 in the equine genital tract vary from that of porcine AWN. HSP-7 appears to be synthesized by A-spermatogonia, caput and corpus epididymal epithelium, seminal vesicle epithelium and from the ampulla of the ductus deferens. On the other hand, porcine AWN is synthesized in the rete testis and the epithelium of the seminal vesicles (Hoshiba and Sinowatz, 1998; Reinert et al., 1997). During passage from the 
caput to the cauda epididymis, decreasing amounts of HSP-7 are present within the seminal plasma (Reinert et al., 1997) while an increased amount is present on spermatozoa (Reinert et al. 1996; Topfer-Petersen et al., 2005).

During epididymal transit and sperm maturation, spermatozoa not only acquire the appropriate molecules for oocyte binding, they also acquire motility. In the stallion, total sperm maturation takes approximately fifty-eight days, which includes development within the testicular parenchyma and movement through the epididymus (McKinnon and Voss, 1992; Senger, 2005). During sexual stimulation, smooth muscle contractions move spermatozoa from the cauda epididymis where motile sperm are stored, into the ductus deferens for ejaculation. The protein coat applied to the spermatozoal surface during sperm maturation and high cholesterol concentration maintains membrane integrity and protects the spermatozoa during passage through the female reproductive tract (Baumber and Meyers, 2006; Landim-Alvarenga et al., 2004; McKinnon and Voss, 1992).

Before spermatozoa are able to bind and fertilize an oocyte, the spermatozoal membrane must be transformed through capacitation and later through the acrosome reaction. Capacitation is characterized by the loss of numerous cholesterol molecules allowing for the destabilization of the plasma membrane and making it more permeable to calcium ions. This allows for the re-organization of proteins within the lipid bilayer (Landim-Alvarenga et al., 2004; Meyers et al. 1995; Senger, 2005). As a result, spermatozoa become 
hypermotile and vesiculation of the plasma membrane and the acrosomal membrane occurs (Pommer et al., 2003). Hypermotility involves a change in motility pattern from a progressively forward motion to non-progressive, whiplike tail movements that aid in the removal of spermatozoa from the epithelial cells lining the oviduct and for penetration through the zona pellucida (McKinnon and Voss, 1992). This is in part how the sperm plasma membrane and biochemistry are altered during capacitation (Landim-Alvarenga et al., 2004; Meyers et al., 1995).

Capacitation appears to be controlled through cyclic AMP (cAMP) dependent signaling pathways and tyrosine phosphorylation (Harrison, 2003; Pommer et al., 2003). Bicarbonate and calcium primarily mediate the activation of adenylyl cyclase and the destruction of phosphodiesterase, leading to an increase in cAMP and further activating adenylyl cyclase and protein kinase A (Harrison, 2003; Pommer et al., 2003). In vivio, the initial phases of capacitation are dependent on glycosaminoglycans such as hyaluronic acid. Glycosaminoglycans are long and linear with strongly acidic repeating units of D-glucosamine and hexuronic acid residues (Calvete et al., 1996). They are naturally secreted by the female reproductive tract and interact with the sperm surface via heparin binding proteins (Calvete et al., 1995). They have a wide variety of physiological roles that modulate the activity of the proteins to which they bind (Calvete et al., 1996). Heparinbinding proteins bind spermatozoa through epididymal transit in a $\mathrm{pH}$, 
calcium, and temperature dependent fashion (Miller et al., 1992) where they facilitate the vesiculation of the plasma membrane and acrosomal membranes (Pommer et al., 2003).

While in vivo capacitation requires glycosaminoglycans from the female reproductive tract, in vitro capacitation appears to require additional substrates. In vitro capacitation is generally observed in either a defined $\mathrm{NaHCO}_{3}$ media (Pommer et al., 2003) with the addition of bovine serum albumin (BSA) (Cross, 1998; Visconti et al., 1999) or the combination of dibutyryl cyclic AMP (dbcAMP) and caffeine (Pommer et al. 2003; Vandevoort et al., 1994). The addition of dbcAMP and caffeine to stimulate capacitation has been used with success in macaque spermatozoa (Boatman and Bavister, 1984) and only recently been used in capacitation of equine spermatozoa (Pommer et al., 2003, Vandevoort et al., 1994). Both species are unique in that they do not spontaneously capacitate in vitro but require chemical modification (Baumber and Meyers, 2006).

Bicarbonate activates soluble adenylate cyclase in the cytoplasm, which results in an increase in cAMP (Baumber and Meyers, 2006). The calcium influx due to an increase in cAMP and increased calcium permeability is a biphasic process occurring once during capacitation and again during the acrosome reaction (Landim-Alvarenga et al., 2004). The addition of dbcAMP and caffeine in vitro stimulates this necessary calcium influx for capacitation to take place (Parris et al., 1999). All in vitro protocols have been designed to 
mimic the effects of glycosaminoglycans present in the female reproductive tract. The most important aspect of capacitation is that it enables sperm to recognize the zona pellucida and undergo the acrosome reaction.

The acrosome reaction is the step following capacitation and can only occur with post-capacitated spermatozoa. The acrosome reaction is defined as the loss of the acrosomal protein matrix, releasing enzymes such as hyaluronidase, proacrosin/acrosin and lipases. The release of enzymes enables the spermatozoon to digest through the zona pellucida and enter the perivitelline space. Premature release of the acrosomal enzymes, or an incomplete or absent acrosomal reaction will all preclude fertilization. However, an intact outer acrosomal membrane will also prohibit sperm-oocyte binding. With the acrosome reaction, receptors are exposed on the equatorial segment to allow complementary molecules arranged on the spermatozoa to interact with the extracellular glycoprotein matrix encasing the oocyte (McKinnin and Voss, 1992, Pommer et al., 2003; Reinert et al., 1996, Senger, 2005). In vitro protocols have been designed to induce the acrosome reaction through chemical and biological agents including calcium ionophores, follicular fluid, zona pellucida glycoproteins, platelet-activating factor, glycosaminoglycans and progesterone (Meyers et al., 1995). Progesterone is often used because it is likely to be present in oviductal fluids and within the cumulus cells of the ovulated oocyte (Linford et al., 1992; Meyers et al., 1995). Meizel and co-workers have studied progesterone induced acrosome 

difficult to obtain for use in sperm-oocyte binding assays. Transvaginal ultrasound guided follicular aspiration (TVA) has been investigated and provides a powerful tool for obtaining in vivo matured oocytes. Purcell et al. (2007) have used equine follicle stimulating hormone (eFSH) within maturation media and have alluded to promising results for equine in vitro oocyte maturation. Bruck and coworkers (1997) reported that the optimal time interval between repeated aspirations is approximately one week to 23 days.

Additionally, cryopreservation of oocytes could relieve dependency upon freshly collected oocytes. Cryopreservation of oocytes allows for cells to remain viable after long-term storage and thawing (Begin et al., 2003). Since oocytes are extremely vulnerable to cryoprotectants, vitrification was designed. Vitrification is defined as glass-like solidification achieved through the use of high concentrations of cryoprotectants combined with rapid cooling (Begin et al., 2003). The rapid cooling rate reduces any toxicity associated with high concentration cryoprotectants and avoids the formation of ice crystals within the oocyte that may cause damage (Begin et al., 2003). Many vitrification techniques have been practiced including solid-surface vitrification (Begin et al., 2003), cryoloop vitrification (Begin et al., 2003; Mavrides and Morroll, 2002) and the traditional method of using $0.25 \mathrm{cc}$ semen straws (Albarracin et al., 2005). Fertilization using cryopreserved equine oocytes has only been reported twice (Hochi et al., 1994; Maclellan et al., 2001), while Checura and Seidel (2007) in their review article reported numerous 
references for bovine cryopreserved oocyte survival. The primary goal of equine oocyte vitrification is to create a protocol for in vitro fertilization. Sperm-oocyte binding assays have provided a valuable tool for understanding sperm mediated steps of fertilization in humans, bulls and boars (Meyers et al., 1996). Sinowatz and coworkers (2003) presented data that equine spermatozoa were observed in the perivitelline space and in the cytoplasm of bovine oocytes during sperm-oocyte binding assays (Sinowatz et al., 2003). The use of equine spermatozoa and bovine oocytes may be a valuable solution to studying equine sperm-oocyte binding during the interim of developing an equine oocyte vitrification protocol where equine oocytes may be more readily available.

Many studies are focused on reaching a deeper understanding of the molecular components involved in equine fertilization. The development of artificial reproductive technologies in the horse has increased steadily over the past two decades, but techniques such as TVA, oocyte vitrification and in vitro fertilization/oocyte binding are not commercially available. Using these techniques in breeding practices and research laboratories could dramatically improve the genetic population and could lead to the identification of many molecules pertinent to fertilization. The discovery of porcine AWN and its involvement in sperm capacitation and fertilization has brought a lot of attention to spermadhesin proteins found in other species. To date, HSP-7 is the only spermadhesin molecule found in the equine specie that has a role in 
sperm capacitation and zona pellucida binding. Minimal studies have been conducted to understand the physiological role of HSP-7 and therefore, HSP7 deserves further study to understand it true role in equine reproduction and how it differs from the role of AWN. 


\section{CHAPTER 2}

\section{INTRODUCTION}

Mammalian fertilization involves sperm capacitation, gamete recognition, and sperm binding to the ovum. These events are mediated by specific interactions between molecules located on the surface of both gametes (Yanagimachi, 1994). The current evaluation of stallion fertility is assessed subjectively through semen parameters (motility, concentration and morphology) and by looking at the previous breeding records of the stallion. These parameters are restricted to the physical characteristics of spermatozoa rather than the molecular components, which may be a more accurate indicator of fertility.

Seminal plasma proteins are attached to the sperm surface during epididymal transit and participate in the fertilization capability of spermatozoa. Spermadhesins are one of the many protein families found within seminal plasma and have been identified in a variety of ungulate species including porcine, bovine and equine. Boar spermadhesins have attracted researchers over the last decade due to their participation in capacitation. Porcine AWN is the most studied spermadhesin molecule across species and is intimately associated with sperm capacitation and zona pellucida binding. AWN is localized to the acrosomal cap of spermatozoa and may play a role in stabilizing the plasma membrane for capacitation. On the other hand, 
equatorial segment binding of HSP-7 suggests a strong role in zona pellucida binding rather than sharing AWN's role in capacitation. The similarities and differences observed between spermadhesin molecules of different species raises the question of whether spermadhesin molecules have different functional roles in reproduction.

To better understand the possible roles of equine HSP-7, we assessed the localization and abundance of HSP-7 on ejaculated (neat) and post capacitated spermatozoa. To date, the characteristics of HSP-7 between fertile and sub-fertile stallions have not been documented. With the proposed role of HSP-7 in fertilization, a variation in relative protein abundance may exist between these two populations of stallions and was a goal of this study to further identify HSP-7's functional role in reproduction.

Further evaluation of the physiological role of HSP-7 in the molecular events of reproduction will be conducted through assisted reproductive techniques (ART). The goal of ART in this study is to obtain equine oocytes via transvaginal ultrasound-guided follicular aspiration for the use in spermoocyte binding assays. This will allow the subpopulation of cells that bind zona pellucida encased oocytes to be evaluated for their immunofluorescent pattern. In combination, these studies will provide evidence of the extent to which HSP-7 and AWN are physiologically homologous. 


\section{MATERIALS AND METHODS}

\section{Chemicals and Media}

Unless otherwise stated, chemicals were obtained from Sigma Aldrich (St. Louis, MO). Primary antibody, porcine polyclonal anti-AWN was kindly donated by Dr. V. Jonakova (Czech Republic) (Jonakova et al., 1998). Secondary antibody, alexa fluor 488 goat-rabbit $\lg G(H+L)$ was obtained from Invitrogen (Carlsbad, CA), $\beta$-tubulin (H-235) and actin antibodies (sc-47778), propidium iodide (PI; sc-3541) and low range protein standards (sc-2360) were purchased from Santa Cruz Biotechnology (Santa Cruz, CA). All centrifugation and incubations were conducted at room temperature unless otherwise noted. Antibodies were diluted with $1 \%$ bovine serum albumin (BSA) in tris-buffered saline (TBS) for all incubations.

\section{Animals}

Semen was obtained from four fertile and two sub-fertile stallions. Stallion fertility was determined by evaluating previous breeding records of each stallion. Stallions were classified as being fertile with a conception rate of greater than or equal to $60 \%$, while sub-fertile stallions were classified based on a conception rate less than $60 \%$. Four stallions were individually housed at the California Polytechnic State University Equine Center, San Luis Obispo and collected from December 2007 through June 2008. In addition, 
two stallions were individually housed at University of California-Davis Equine Research Laboratory (School of Veterinary Medicine) and collected during January 2008. A total of 16 ejaculates from fertile stallions and 25 ejaculates from subfertile stallions were used in this study. All horses were maintained according to Institutional Animal Care and Use Committee protocols at each university.

\section{Semen Collection}

Semen was collected using a phantom mare and a Missouri artificial vagina with a nylon mesh filter to allow the sperm rich fraction to enter the collection bottle. Post ejaculation sperm concentration was determined using an Equine Densimeter (Animal Reproductive Systems; Chino, CA).

Immediately, the sperm rich fraction was diluted to $50 \times 10^{6}$ cells $/ \mathrm{ml}$ using $37^{\circ} \mathrm{C}$ modified-TALP (Bavister, 1989, see below: Appendix A). Modified-TALP was prepared with Tyrode's balanced salt solution ( $\mathrm{pH} 7.4,290-300$ mOsm) supplemented with $25 \mathrm{mM} \mathrm{NaHCO}_{3}, 10 \mathrm{mM}$ sodium lactate, $0.1 \mathrm{mM}$ sodium pyruvate, $3 \mathrm{mg} / \mathrm{ml} \mathrm{BSA}$, penicillin $\mathrm{G}$ and streptomycin. Modified-TALP was made fresh the day prior to each stallion collection and incubated overnight at $37^{\circ} \mathrm{C}$ with $5 \% \mathrm{CO}_{2}$ to reach physiological temperature. Diluted semen was transported to the laboratory within 10 minutes of collection for processing. 
Sperm Processing for Percoll Centrifugation and In Vitro Capacitation

Upon arrival in the laboratory, sperm parameters, including concentration, motility and morphology, were measured using a Makler counting chamber (Irvine Scientific; Santa Ana, CA) according to the manufacturer's protocol. Sperm morphology was determined according to the Society of Theriogenology guidelines (Kenney et al., 1983). Samples were subsequently processed for Percoll centrifugation and capacitation, with slight modification to the protocol described by Meyers et al. (2003). Samples were centrifuged at $400 \times \mathrm{g}$ for $5 \mathrm{~min}$ to sediment debris and pellet sperm which was re-suspended in $4 \mathrm{ml}$ modified-TALP. A 90\% Percoll solution was prepared by adding 10x modified-TALP to $100 \%$ Percoll. This solution was diluted with $1 \mathrm{x}$ modified-TALP to produce $84 \%$ and $42 \%$ gradients. Two $\mathrm{ml}$ of semen solution was layered over two Percoll-TALP gradients consisting of an $84 \%$ (lower) and $42 \%$ (upper) layer. After $20 \mathrm{~min}$ of centrifugation at $400 \mathrm{x} \mathrm{g}$, the sperm pellet was collected and re-suspended in $4 \mathrm{ml}$ of modified-TALP to wash cells of Percoll residue. The sperm suspension was centrifuged at $300 \mathrm{x}$ $\mathrm{g}$ for $5 \mathrm{~min}$ and the pellet was re-suspended in $1 \mathrm{ml}$ of modified-TALP. An aliquot was processed for fixation (see below: Sperm Processing for Fixation) while the remainder was prepared for capacitation by determining the concentration using a Makler counting chamber and adjusting with modifiedTALP to a final concentration of $20 \times 10^{6} \mathrm{cell} / \mathrm{s} / \mathrm{ml}$. In microcentrifuge tubes, 500ul of post Percoll sperm suspension was incubated at $37^{\circ} \mathrm{C}$ and $5 \% \mathrm{CO}_{2}$ 
with the lids open to prime cells for capacitation. After 1 hour of incubation, the incubator was adjusted to $38.5^{\circ} \mathrm{C}$ which slowly reached peak temperature in approximately 1 hour. Total incubation was equivalent to 2 hours. A final concentration of $1 \mathrm{mM}$ of dibutyryl cyclic AMP (dbcAMP) and $1 \mathrm{mM}$ caffeine were added to the sperm suspension and incubated for an additional $30 \mathrm{~min}$ at $38.5^{\circ} \mathrm{C}$ and $5 \% \mathrm{CO}_{2}$ to activate capacitation.

\section{Sperm Processing for In Vitro Acrosome Reaction}

The acrosome reaction was induced according to Meyers et al. (1995). Two aliquots were incubated for an additional $10 \mathrm{~min}$ at $38.5^{\circ} \mathrm{C}$ in $5 \% \mathrm{CO}_{2}$ with $10 \mathrm{ug} / \mathrm{ml}$ progesterone suspended in dimethyl sulfoxide. Post incubation, samples were centrifuged at $3000 \mathrm{xg}$ for $1 \mathrm{~min}$, supernatant was removed and the pellet was washed in $1 \mathrm{ml}$ modified-TALP. A sperm pellet was formed by centrifugation at $3000 \times \mathrm{g}$ for $3 \mathrm{~min}$ and supernatant was removed. The sperm pellet was washed twice in Dulbecco's phosphate buffered saline (DPBS) through centrifugation at $3000 \times \mathrm{g}$ for $3 \mathrm{~min}$. Following centrifugation and 2 washes in DPBS at $3000 \times \mathrm{g}$ for 3 minutes, an aliquot was processed for fixation (see below: Sperm Processing for Fixation) while the remainder was prepared for evaluation of the acrosome reaction.

To determine the rate of the acrosome reaction, cells were incubated with $100 \mathrm{ug} / \mathrm{ml}$ fluorescein isothiocyanate Arachis hypogaia (FITC-PSA) and 
2.4mM propidium iodide $(\mathrm{PI})$ for 10 minutes, covered from light. Cells were centrifuged at $8000 \times \mathrm{g}$ for 3 minutes and the pellet was re-suspended in approximately 250ul DPBS depending on pellet size. Cells were mounted on microscope slides with a drop of Vectashield (Vector Laboratories; Burlingame, CA) and evaluated with an Axioskop 40 epifluorescent microscope (Carl Zeiss; Thornwood, NY) fitted with a dual filter set (Excitation 485/20 and 546/12 with emission 515-530 and 580-630). Differential fluorescence (FITC-PSA, green; PI, red) was used to evaluate the acrosomal integrity of each spermatozoon. The acrosomal integrity was determined on 100 cells. Sperm with bright or thin green fluorescence over the acrosomal region in conjunction with a red nucleus were scored as having an intact acrosome. Sperm lacking an acrosomal matrix or a lack of green fluorescence were scored as having a reacted acrosome.

\section{Sperm Processing for Fixation}

Aliquots of neat, post in vitro capacitated and post acrosomal reacted cells were processed for fixation. Samples were centrifuged at $3000 \mathrm{x} \mathrm{g}$ for 4 min to remove excess media. Cells were washed twice in modified-TALP through centrifugation prior to incubation in $2 \%$ paraformaldehyde (EM grade) in DPBS for 40 min. Samples were centrifuged at $3000 \times \mathrm{g}$ for $4 \mathrm{~min}$ and washed twice with DPBS. The sperm pellet was re-suspended in DPBS at an 
approximate concentration of $50 \times 10^{6}$ cells $/ \mathrm{ml}$ with $1 \mathrm{ul}$ of $50 \times$ penicillinstreptomycin cocktail. Samples were stored at $4^{\circ} \mathrm{C}$ in Parafilm wrapped sterile cryovials.

Indirect Immunofluorescent Microscopy

The topography of HSP-7 epitopes on ejaculated equine spermatozoa was conducted, according to Kraus et al. (Kraus et al., 2005). Sperm cell suspension $\left(\sim 5 \times 10^{6}\right)$ was spread onto coverslips surrounded by a hydrophobic barrier (PAP Pen; Invitrogen; Carlsbad, CA). Suspension remained at ambient temperature to dry ( $\sim 20 \mathrm{~min})$. An aliquot of cells were permeabilized by exposure to ethanol $\left(-20^{\circ} \mathrm{C}\right)$ for 5 minutes. Fixation was accomplished by the use of methanol $\left(-20^{\circ} \mathrm{C}\right)$ for 5 minutes. Nonpermeabilized cells were only exposed to methanol. After the cells were fixed, they were washed 3 times with DPBS. Cells were incubated for 30 minutes in blocking solution (10\% BSA in DPBS) and thoroughly washed with DPBS. Coverslips were incubated with anti-AWN (1:5000) for 2 hours at $37^{\circ} \mathrm{C}$. Following incubation with primary antibody and 3 washes for 4 min each with DPBS, cells were incubated with Alexa Fluor 488 goat anti-rabbit $\lg$ (1:200) for 1 hour at $37^{\circ} \mathrm{C}$, covered from light. Coverslips were mounted on glass slides using Vectashield (Vector Laboratories; Burlingame, CA) and viewed using the Zeiss Axioskop 40 epifluorescent microscope (Carl Zeiss; Thornwood, NY). 


\section{Protein Extraction}

Total sperm protein from neat and post capacitated cells was isolated according to Ekhlasi-Hundrieser et al., 2005. Sperm samples $\left(\sim 10^{7}\right.$ cells $)$ were separated from seminal plasma by centrifugation at $3000 \times \mathrm{g}$ for 5 minutes at $4^{\circ} \mathrm{C}$. Seminal plasma supernatant was removed and the sperm pellet was re-suspended and washed twice in modified-TALP. The final sperm pellet was re-suspended in 3 pellet volumes ( 200ul) of extraction buffer (10mM Tris-HCL, pH 7.4, 10\% sucrose, $1 \mathrm{mM}$ ethlyenediaminetetraacetic acid (EDTA), $1 \%$ sodium dodecyl sulfate (SDS), 2ul protease inhibitor) and allowed to extract on ice for 2 hours. Sperm debris was removed by centrifugation at $13000 \mathrm{xg}$ for 20 minutes at $4^{\circ} \mathrm{C}$. Soluble protein supernatant was stored at $20^{\circ} \mathrm{C}$ until used for SDS-PAGE. Protein content of each extract was determined using bicinchoninic acid protein assay kit (BCA kit; Pierce; Rockford, IL).

\section{Western Blotting}

A polyclonal antibody directed against purified $A W N$ was raised in rabbit (Jonakova et al., 1998) and tested for specificity as described in Sinowatz et al. (1995). Prior to SDS-PAGE, total protein samples were thawed and vortexed. Fifty-five ug of total protein were premixed with $33 \% \mathrm{v} / \mathrm{v}$ bromophenolblue loading buffer ( $4 \mathrm{X}$ loading buffer diluted to $1 \mathrm{X}$ with glycerol 
and 10ul $\beta$-mercaptoethanol; 4X loading buffer: $13.3 \%$ SDS, 0.42M Tris, $0.013 \%$ bromophenolblue, $\mathrm{pH}$ 6.5). Samples were heated for 3 minutes at $99^{\circ} \mathrm{C}$ and subsequently cooled for 2 minutes prior to loading into each well of 12\% Tris-HCL precast gels (Bio Rad; Hercules, CA). Electrophoresis was performed at $40 \mathrm{~V}$ for approximately 4 hours and the gel was then blotted onto a nitrocellulose membrane (Millipore; Billerica, MA). The membrane was washed in tris-buffered saline containing $0.1 \%$ Tween 20 (TBS-T). Total protein was visualized using Ponceau S (0.1\% w/v in 5\% acetic acid) according to the manufacturer's protocol. After the membranes were visualized using a gel-doc system (Bio Rad; Hercules, CA), the membranes were stripped of antibodies for 1 hour at $50^{\circ} \mathrm{C}$ in stripping solution $(3.1 \mathrm{ml} 1 \mathrm{M}$ Tris at $\mathrm{pH} 6.7,10 \% \mathrm{SDS}, 352 \mathrm{ul} \beta M E$ and $36.5 \mathrm{ml} \mathrm{H}_{2} \mathrm{O}$ ). After blocking for 2 hours with 5\% BSA in TBS-T, the membranes were washed in TBS-T and incubated with porcine anti-AWN (1:1000) overnight at $4^{\circ} \mathrm{C}$ on an orbital rotator. The nitrocellulose membrane was washed 3 times for 4 min each with TBS-T and incubated with goat anti-rabbit IgG conjugated with alkaline phosphatase (GAR IgG-AP; 1:5000) on an orbital rotator for 1 hour at room temperature. After 3 additional washes in TBS-T, alkaline phosphatase activity was visualized using the Immun-Star detection kit (Bio Rad; Hercules, CA) according to the manufacturer's protocol. Membranes were visualized using a chemiluminescence gel-doc system (Bio Rad; Hercules CA).

Membranes were stripped of antibodies and blocked in 5\% BSA as 
described and subsequently incubated with either the primary antibody actin or $\beta$ tubulin (1:5000) for two hours. Actin and $\beta$ tubulin were individually used as loading controls. Immun-Star detection kit and secondary antibody were the same as previously described. Low range protein standard was used to assess the molecular weights of the protein bands.

\section{Equine Transvaginal Follicular Aspiration}

Transvaginal ultrasound-guided follicular aspiration (TVA) was conducted with modification, according to Coutinho da Silva et al. (2002) and Purcell et al. (2007). For all procedures, the mares were restrained in the breeding stocks at California Polytechnic State University, Equine Center and sedated as necessary with zylazine hydrochloride $(0.6 \mathrm{mg} / \mathrm{kg}$, IV; Pfizer, New York, NY). Follicular development was monitored by transrectal ultrasound examination of the ovaries. Follicles of $40 \mathrm{~mm}$ in size or greater were used for follicular aspiration and prior to the aspiration procedure, mares were administered zylazine hydrochloride (0.6 mg/kg, IV; Pfizer, New York, NY) and butorphanol tartrate $(0.1 \mathrm{mg} / \mathrm{kg}$, IV; Pfizer, New York, NY) for sedation and analgesia. In addition, all mares received Buscopan ( $\mathrm{N}$ butylscopolammonium bromide, $0.3 \mathrm{mg} / \mathrm{kg}$, IV; Boehringer Ingelheim, Germany) to induce rectal relaxation. Transvaginal ultrasound-guided follicle aspiration was performed using a $5 \mathrm{MHz}$ curvilinear transducer housed in a 
hard plastic casing with an external needle guide covered in a disposable sterile sleeve. An 18-gauge, $60 \mathrm{~cm}$ single lumen ovum aspiration needle (VOPAA-1860, Cook Medical, Australia) was attached to a 60cc syringe and inserted into the needle guide for aspiration. After cleaning the perineal region with soap and water, the transducer was sterilely introduced into the fornix vagina while the ovary was stabilized against the transducer per rectum palpation. The preovulatory follicle was aspirated by positioning the ovary against the face of the transducer and the needle was advanced into the follicle. While puncturing the follicle, constant negative pressure was applied within the follicular antrum and the needle was slowly rotated and used to lightly scrape the follicular wall, in an attempt to dislodge the oocyte.

Follicular fluid was evaluated with a dissecting microscope for cumulusoocyte complexes immediately after aspiration. Complexes were transported to the laboratory in follicular fluid where they were transferred to a microdroplet of maturation media (Gibco, NY) and maintained at $39^{\circ} \mathrm{C}$ and $5 \%$ $\mathrm{CO}_{2}$ until processed for vitrification within one hour of incubation. No attempt was made to conduct in vitro maturation.

\section{Bovine Oocyte Collection}

Bovine ovaries were collected from a regional abattoir and transported to the reproductive physiology laboratory within three hours in DPBS maintained 
at $37^{\circ} \mathrm{C}$. Upon arrival, ovaries were rinsed and then held in DPBS at $37^{\circ} \mathrm{C}$ until aspiration. Aspiration was conducted using a $20 \mathrm{cc}$ syringe and an 18gauge needle. Upon entry into the follicle, constant negative pressure was applied within the antrum to remove the follicular fluid. The follicular fluid was also used to flush each antrum twice. With a dissecting microscope, follicular fluid was evaluated for cumulus-oocyte complexes which were transferred to sterile Petri dishes containing microdroplets of maturation media (Gibco, NY) and cultured in an incubator maintained at $39^{\circ} \mathrm{C}$ and $5 \% \mathrm{CO}_{2}$ until vitrification within one hour of incubation. No attempt was made to conduct in vitro maturation.

\section{Bovine and Equine Oocyte Vitrification and Thaw}

With slight modification, vitrification of equine and bovine oocytes were conducted according to Maclellan et al. (2002). Cumulus oocyte complexes were removed from the incubator and gently pipetted with a large-bore pipette repeatedly until 8-10 cumulus cell layers remained surrounding the oocyte. Oocytes were passed through three cryoprotectant solutions prior to being loaded onto the cryoloop. The three cryoprotectant solutions are as follows: 5\% DMSO (0.7M) and 5\% ethylene glycol (EG; 0.9M) in Medium 199 (M199) for 30 sec.; $10 \%$ DMSO (1.4M) and 10\% EG (1.8M) in M199 for 30 sec.; $20 \%$ DMSO (2.8M), 20\% EG (3.6M), 10mg/ml ficoll with $0.65 \mathrm{M}$ sucrose in M199 
for $20 \mathrm{sec}$. After passage through the cryoprotectants, oocytes were loaded onto a 0.5-0.7 mm diameter nylon loop, mounted on a stainless steel rod inserted into the lid of a two ml cryovial (Hampton Research, Laguna Niguel, $\mathrm{CA}$ ) and directly plunged into liquid nitrogen.

To thaw, the nylon loop was removed from the cryovial and immerged in three different solutions: $0.25 \mathrm{M}, 0.188 \mathrm{M}$ and $0.125 \mathrm{M}$ sucrose in $\mathrm{M} 199$ at $39^{\circ} \mathrm{C}$ for $30 \mathrm{sec}$. each. Ooctyes were placed in individual microdroplets of fertilization media (Gibco, NY) in an incubator maintained at $39^{\circ} \mathrm{C}$ and $5 \%$ $\mathrm{CO}_{2}$ to equilibrate for one hour before being used for binding assays.

Sperm-Oocyte Binding: In vitro fertilization, Fixation and Immunofluorescence

In vitro fertilization (IVF) was conducted, according to Sinowatz et al. (2003). Co-incubation occurred in a microdroplet of fertilization media with 20 $X 10^{6}$ capacitated spermatozoa with individual oocytes at $5 \% \mathrm{CO}_{2}$ at $38.5^{\circ} \mathrm{C}$ for four hours. After incubation, sperm-oocyte complexes were passed though a wide bore pipette repeatedly to remove any loosely bound sperm and washed through three wells of fertilization media. Sperm-oocyte complexes were added to a 100 ul droplet of $2 \%$ paraformaldehyde in DPBS for 40 min at room temperature. After washing through three droplets of DPBS, spermoocyte complexes were incubated in 5\% BSA and DPBS overnight at $4^{\circ} \mathrm{C}$. After washing the sperm-oocyte complexes in DPBS, the complexes were 
incubated with anti-AWN, at a dilution of 1:5000 in 1\% BSA for two hours at $37^{\circ} \mathrm{C}$. Following three washes in DPBS, sperm-oocyte complexes were incubated with secondary antibody, Alexa 488 rabbit anti-goat IgG in $1 \%$ DPBS, for one hour at $37^{\circ} \mathrm{C}$ with one ul $(2.4 \mathrm{mM}) \mathrm{PI}$. Post incubation and three washes through DPBS, complexes were mounted onto microscope slide with Vectashield and visualized with Zeiss Axioskop 40 epifluorescent microscope fitted with a dual filter set (Alexa, green; PI, red) for observation of differential fluorescence (Carl Zeiss, NY).

\section{Statistical Analysis}

Data were analyzed using ANOVA and Students paired t-test. A variable or set of variables was considered significant at $P<0.05$. All statistical analyses were carried out using Minitab Release 14 statistical package and Microsoft Excel 2008 for Mac. 


\section{RESULTS}

Validation of HSP-7 Antibody

The specificity of the primary antibodies used in this study were confirmed using both positive and negative controls. The negative control for the anti-AWN antibody was constructed by individually omitting both the primary and secondary antibody from the immunofluorescence protocol. When these sperm cells were analyzed using fluorescent microscopy, no fluorescence was observed (Figure 4). The positive control for the anti-AWN antibody was conducted according to previous studies (Calvete et al., 1994a; Jonakova et al., 1998).
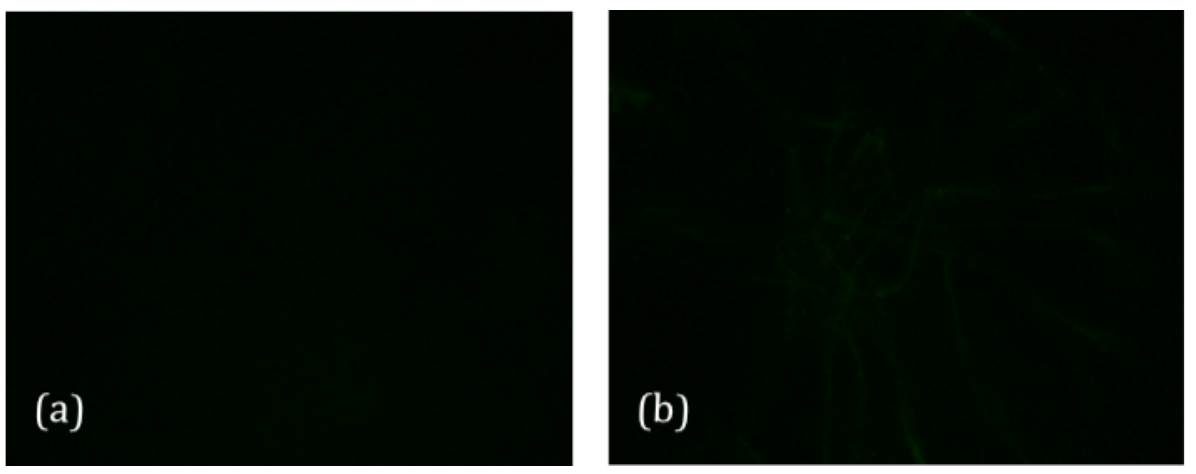

Figure 4. Negative control for anti-AWN polyclonal antibody, with (a) primary antibody and (b) secondary antibody omitted. No immunofluorescence of ejaculated equine spermatozoa is seen. (100 X 10 magnification) 
Indirect Immunofluorescent Microscopy

The localization of HSP-7 on stallion spermatozoa was evaluated through indirect immuofluorescence using a polyclonal antibody produced against porcine AWN (Jonakova et al., 1998), which cross-reacts with HSP-7 (Calvete et al., 1994a). On neat sperm cells obtained during the breeding season, fluorescence was primarily restricted to the equatorial segment (Figure 5a). During the non-breeding season, fluorescence was specific to the midpiece region and the equatorial segment (Figure 5b). Minimal midpiece labeling was observed on spermatozoa that were collected during the breeding season but this localization pattern was inconsistent between samples. Morphologically abnormal spermatozoa labeled for HSP-7 with the same pattern as morphologically normal spermatozoa (Figure 6). Within each sample set, it was observed that individual spermatozoa contain varying amounts of HSP-7 (Figure 7), while only $30 \%$ of the cells labeled for HSP-7 (Figure 8).
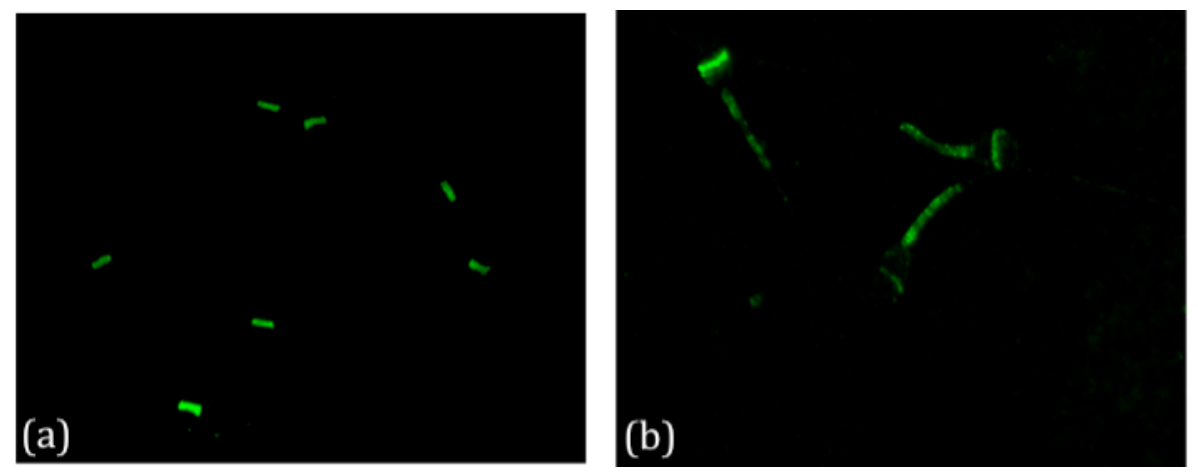

Figure 5. Indirect immunofluorescent labeling of HSP-7 on neat stallion spermatozoa during the (a) breeding and (b) non-breeding season using antiAWN polyclonal antibody. (100 X 10 magnification) 

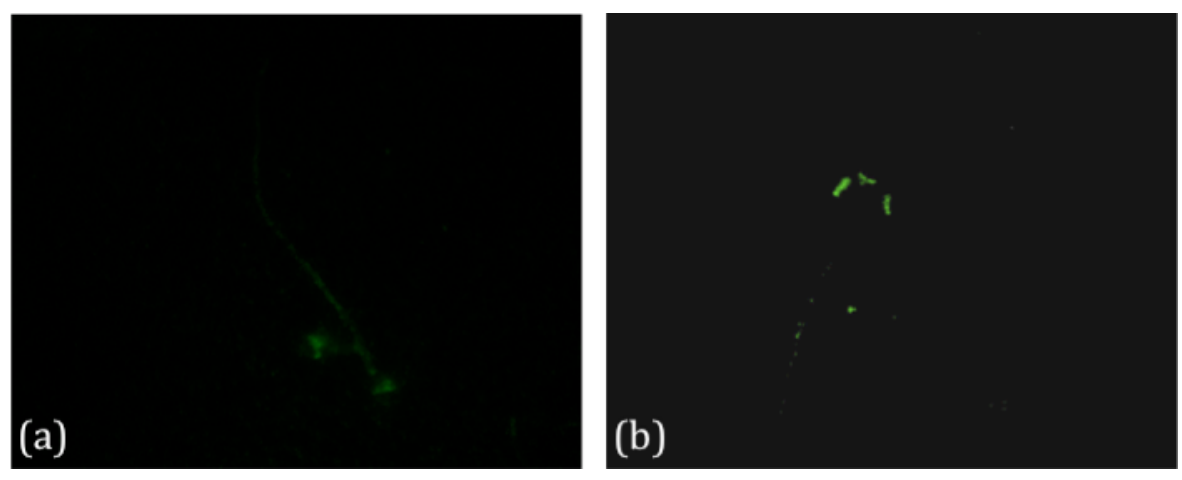

Figure 6. Indirect immunofluorescence of abnormal spermatozoa labeled with anti-AWN polyclonal antibody; (a) double and (b) triple sperm heads. (100 X 10 magnification)

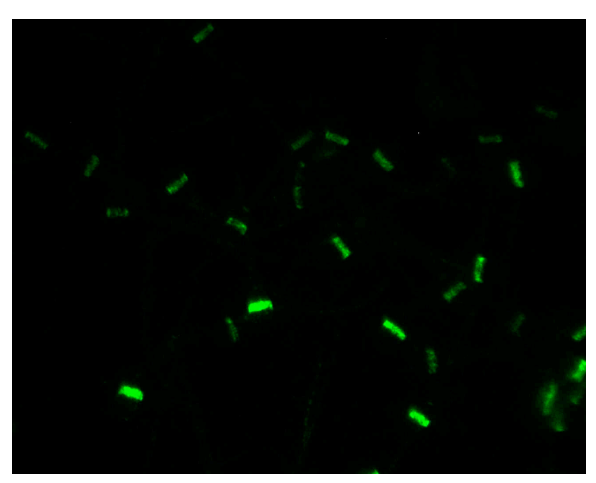

Figure 7. Variation of protein abundance using indirect immunofluorescence of stallion spermatozoa with anti-AWN polyclonal antibody. (100 X 10 magnification)

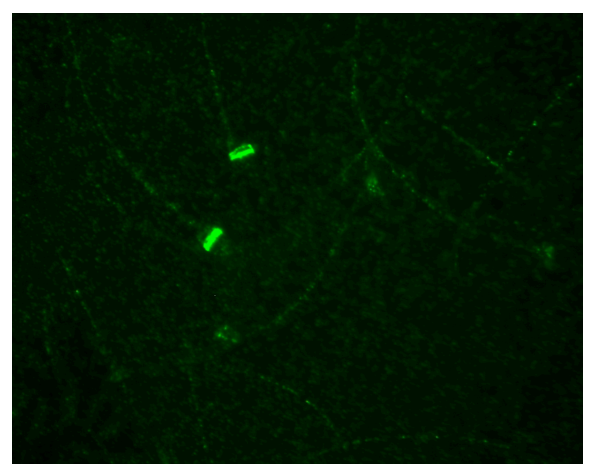

Figure 8. Absence of AWN labeling on neat spermatozoa using indirect immunofluorescence and anti-AWN polyclonal antibody. (100 X 10 magnification) 
Permeabilized cells displayed a different localization pattern from nonpermeabilized cells. Permeabilized cells exhibited HSP-7 localization on the lower half of the sperm head and ubiquitously down the midpiece and principal piece (Figure 9). Some permeabilized cells displayed an additional localization to the capitulum of the principal piece (Figure 10).

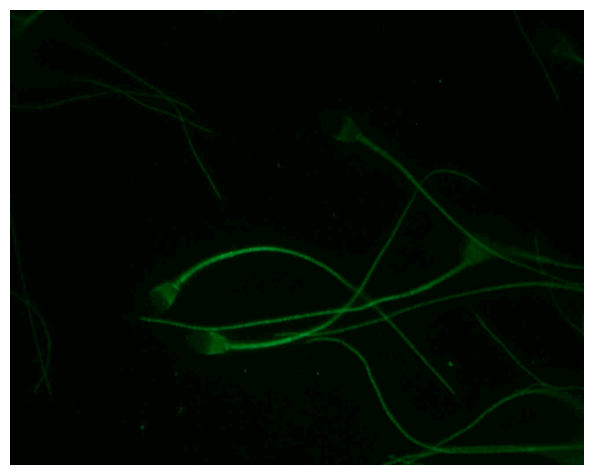

Figure 9. Labeling pattern of ethanol permeabilized stallion spermatozoa using indirect immunofluorescence and anti-AWN polyclonal antibody. (100 X 10 magnification)

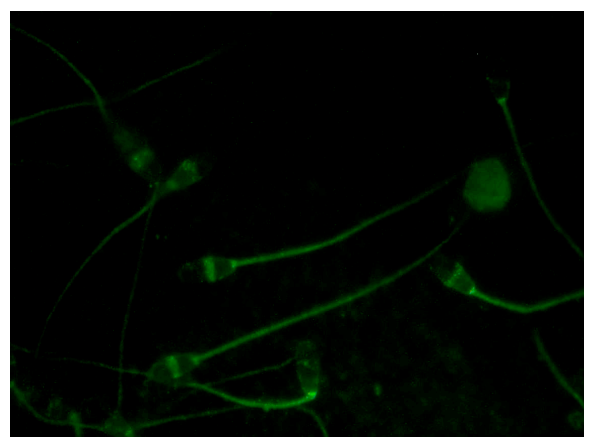

Figure 10. Indirect immunofluorescence of ethanol permeabilized spermatozoa using anti-AWN polyclonal antibody, demonstrating fluorescence of the capitulum region of the sperm tail. (100 X 10 magnification) 


\section{In Vitro Capacitation}

Samples were evaluated through differential immunofluorescence for either an intact acrosome (Figure 11a) or for the absence of an acrosomal cap (Figure $11 b$ ). From the samples evaluated $(n=6)$, an average of $64.6 \%$ of spermatozoa underwent the acrosomal reaction following progesterone treatment (Figure 12). This indicates that $64.6 \%$ of spermatozoa were capacitated after treatment with caffeine and dbcAMP. There was no correlation $(P>0.05)$ observed between fertile and subfertile stallions relative to their ability to undergo capacitation.
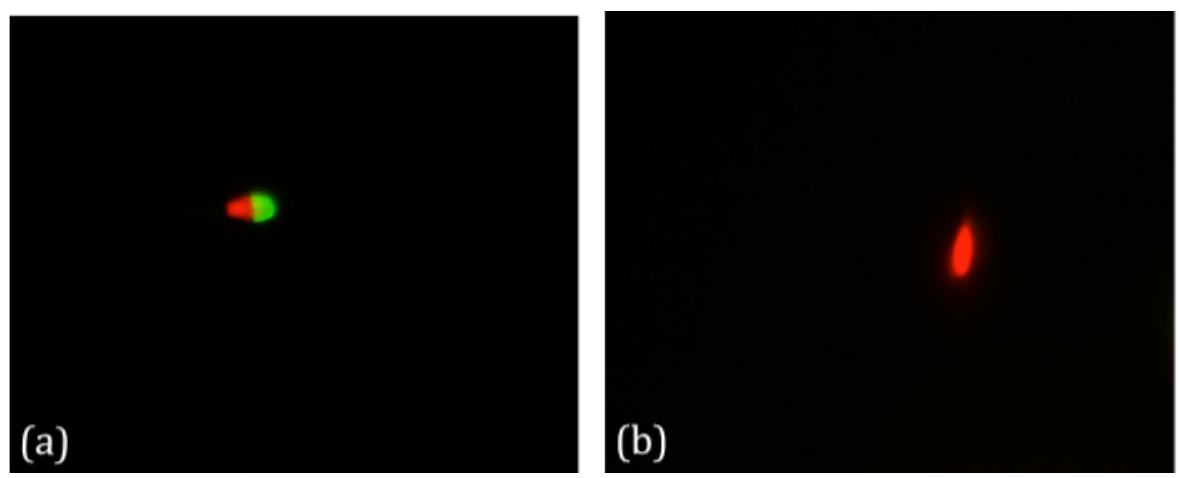

Figure 11. Differential immunofluorescence of capacitated spermatozoa, treated with progesterone FITC-PSA and PI; (a) acrosome intact and (b) acrosome reacted spermatozoa. (100 X 10 magnification) 


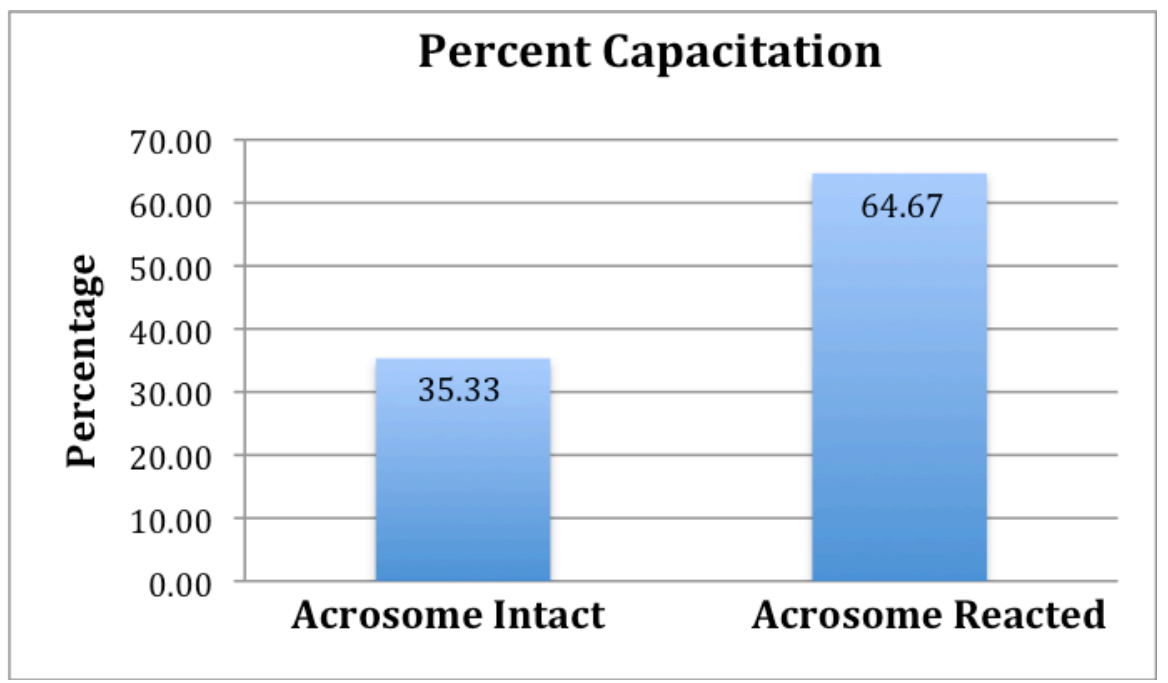

Figure 12. Percent of acrosome reacted spermatozoa depicting the percent of capacitated cells. Percent of acrosome intact cells is equivalent to the percentage of cells which did not capacitate $(P$-value $<0.05)$.

Immunofluorescence of Capacitated and Acrosome Reacted Spermatozoa

Post in vitro capacitated and acrosome reacted spermatozoa displayed a unique labeling pattern between the breeding and non-breeding season.

Cells that underwent capacitation and the acrosome reaction during the breeding season displayed light dappling over the acrosomal cap (Figure 13) while during the non-breeding season, only equatorial and midpiece labeling was observed. Approximately $30 \%$ of the cells did not label for HSP-7. 


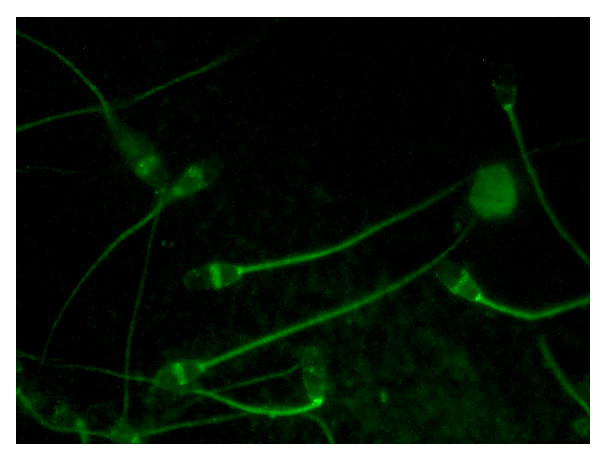

Figure 13. HSP-7 labeling pattern of capacitated spermatozoa collected during the breeding season, using indirect immunofluorescence and anti-AWN polyclonal antibody. (100 X 10 magnification)

\section{Western Blot Analysis}

Western blots indicated that anti-AWN antibody recognizes a single band at $\sim 30 \mathrm{kDa}$ in size (Figure 14). Total sperm protein from stallions of varying fertility were evaluated for HSP-7 abundance which revealed that protein abundance varies between stallions. No significant difference $(P>$ 0.05) was observed between fertile and sub-fertile stallions, but variability in protein abundance was consistent across all samples (Figure 15).

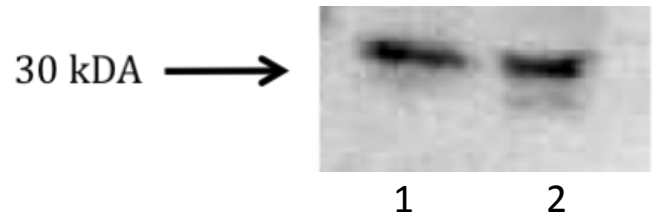

Figure 14. Western blot of (1) detergent extracted sperm protein and (2) seminal plasma. Total protein $(55 \mathrm{ug})$ was loaded into each lane and subjected to $12 \%$ SDS-PAGE, blotted and probed with anti-AWN polyclonal antibody. 


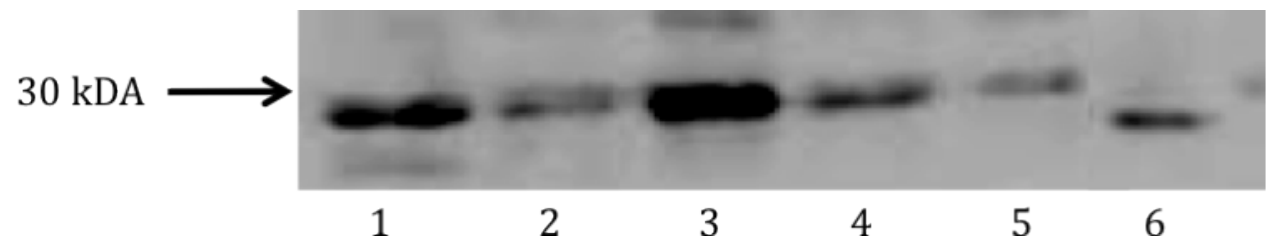

Figure 15. Western blot of detergent extracted sperm protein from fertile (lanes 14) and sub-fertile (lanes 5 and 6 ) during the month of March. Total sperm protein (55ug) was loaded into each lane and subjected to $12 \%$ SDS-PAGE, blotted and probed with anti-AWN polyclonal antibody.

HSP-7 abundance was evaluated over three time intervals: December, March and May. The natural onset of the equine breeding season occurs as early as March and continues through July. HSP-7 abundance peaked during the month of March while during the months of December and May, HSP-7 abundance decreased (Figure 16). The change in protein abundance during these time periods was also analyzed between fertile and sub-fertile stallions. Fertile stallions had greater protein abundance during the month of March when compared between the breeding and non-breeding season (Figure 17a) while sub-fertile stallions did not display the same variation (Figure 17b). (This relationship was not statistically significant $(P>0.05))$.

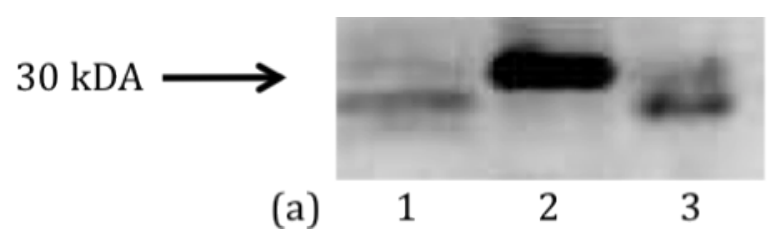

Figure 16. Western blot of detergent extracted protein from a fertile stallion during different times of the year; (1) December, (2) March, (3) May. Total sperm protein (55ug) was loaded into each lane and subjected to 12\% SDS-PAGE, blotted and probed with anti-AWN polyclonal antibody. 


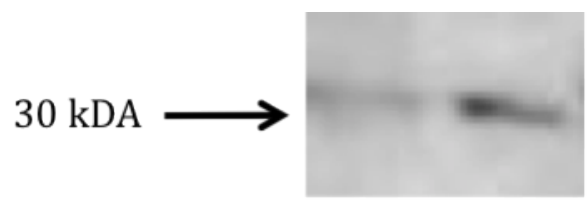
(a) $1 \quad 2$
(b) 1
2

Figure 17. Western blot of detergent extracted sperm protein of (a) fertile and (b) sub-fertile during the (1) non-breeding and (2) breeding season. Total sperm protein $(55 \mathrm{ug})$ was loaded into each lane and subjected to $12 \%$ SDSPAGE, blotted and probed with anti-AWN polyclonal antibody.

When comparing HSP-7 abundance between neat and post capacitated spermatozoa, HSP-7 abundance increased with capacitation $(P<$ 0.05; Figure 18). This relationship was consistent across all samples evaluated, including stallions of high and low fertility. This infers that HSP-7 is exposed with capacitation rather than removed which is documented with AWN. The primary antibodies, beta tubulin and actin were individually used a loading controls (results not shown). While most stallions with high conception rates had a greater abundance of HSP-7 in comparison to stallions with low conception rates, this observation was not consistent across all samples.

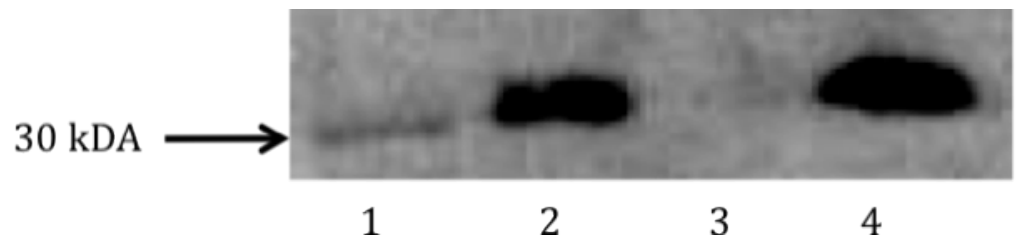

Figure 18. Western blot of detergent-extracted sperm protein from neat (lanes 1 and 3 ) and post in vitro capacitated (lanes 2 and 4) equine spermatozoa. Total protein (55ug) was loaded in each lane and subjected to $12 \%$ SDS-PAGE, blotted and probed with anti-AWN polyclonal antibody. $(P<0.05)$ 
Oocytes were collected through transvaginal ultrasound-guided follicular aspiration (TVA, Figure 19) from mares during estrus. A total of six ooctyes were collected from pre-ovulatory follicles greater than $40 \mathrm{~mm}$ in size (10\% success rate). Individual oocytes were maintained in follicular fluid until processing and no attempt was made to mature oocytes in vitro.

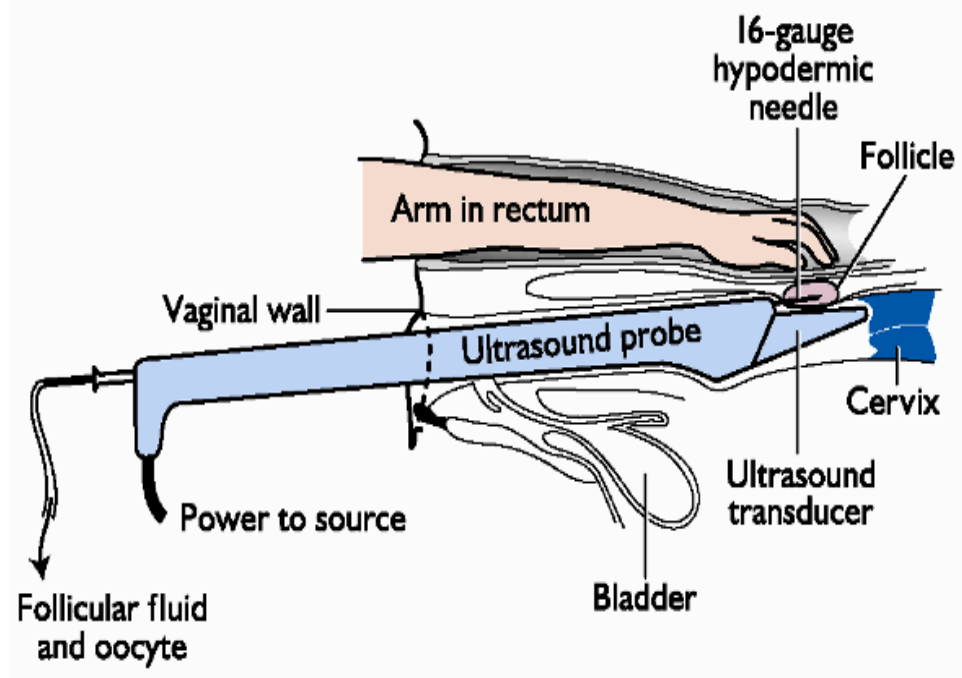

Figure 19. Depiction of transvaginal ultrasound-guided follicular aspiration. (From Senger, 2005)

Vitrification of Bovine and Equine Oocytes

TVA oocytes from mares in estrus $(n=6)$ and bovine oocytes collected from slaughterhouse ovaries $(n=40)$ were used for vitrification using cryoloops. Of the oocytes vitrified, only 20 oocytes total ( 6 equine and 14 
bovine) were thawed and used for in vitro fertilization assays (90\% of the oocytes were vitrified).

Sperm-Oocyte Binding, Fixation and Immunofluorescence

Co-incubation of capacitated spermatozoa with oocytes resulted in a maximum of 12 sperm cells tightly bound to individual oocytes after repeated pipetting through a wide bore pipette (Figure 20). Previous studies have documented success with the formation of sperm-oocyte complexes using equine sperm and bovine oocytes (Sinowatz et al., 2003). Each attempt made to process sperm-oocyte complexes in this study led to the removal of sperm cells from the zona pellucida. While sperm were not detected on the surface of the oocytes during immunofluorescence studies, ubiquitous labeling of HSP-7 was observed over the entire surface of each oocyte (Figure 21).
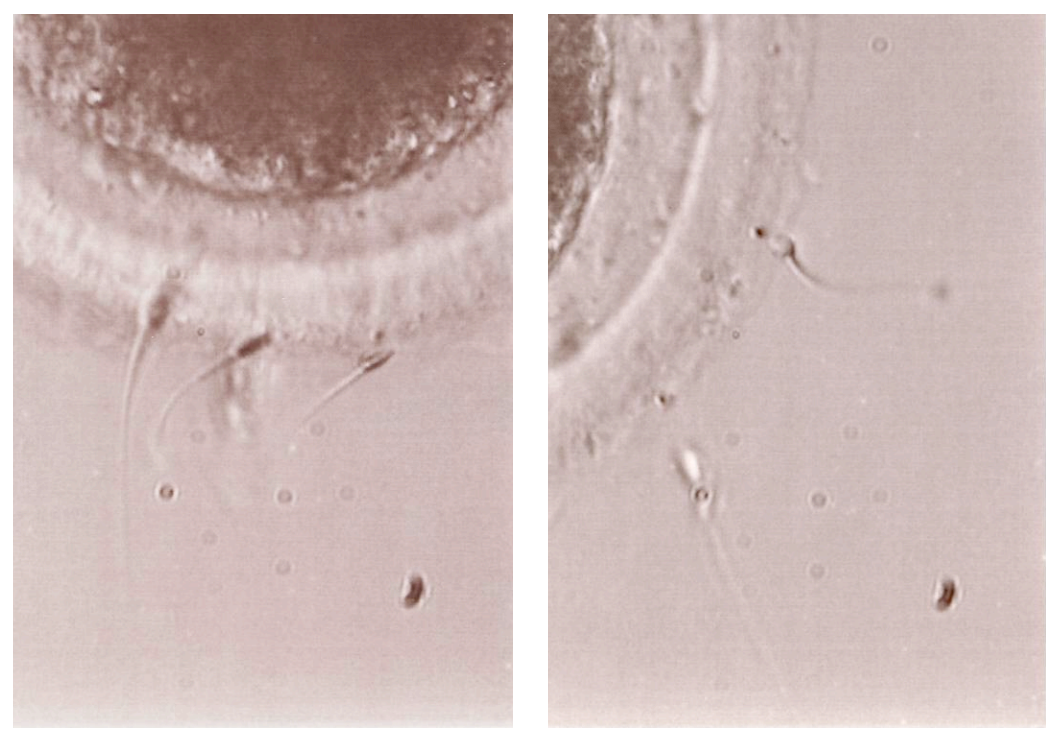

Figure 20. Sperm oocyte binding (4hrs) using capacitated equine spermatozoa and vitrified bovine oocytes. (100 X 10 magnification) 


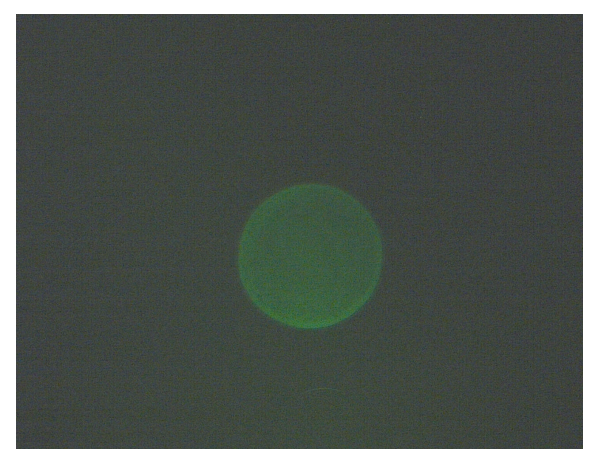

Figure 21. In vitro binding assay using a bovine oocyte with capacitated equine spermatozoa. Spermatozoa were not present however; there was ubiquitous HSP-7 immunofluorescence observed across the surface of the oocyte using anti-AWN polyclonal antibody. (100 X 10 magnification) 


\section{DISCUSSION}

Mammalian fertilization is a complex process where complementary molecules on the surface of morphologically disparate gametes recognize each other, bind and facilitate fusion. This process involves a series of highly coordinated interactions between molecules in the gametes' natural environment and on the surface of the individual gametes. Seminal plasma is the secretory product from the male accessory sex glands (ampulla, seminal vesicles, prostate and bulbourethral glands) which includes both organic and inorganic compounds. Seminal plasma provides many of the necessary molecules for sperm-oocyte binding to occur.

During epididymal transit and ejaculation, seminal plasma proteins bind the sperm plasma membrane, protecting the spermatozoa during transport through the female reproductive tract and optimizing its fertilization capabilities (McKinnon and Voss, 1992). Seminal plasma proteins are known to modulate a variety of spermatozoal functions such as motility, capacitation and the acrosome reaction (Senger, 2005). Numerous seminal plasma proteins have been isolated across species, some of which have homologous primary structures while others not only differ in structure but also in function.

Spermadhesins are a family of secretory proteins expressed in the male reproductive tract of the boar, stallion and bull (Manaskova et al., 2007). Spermadhesins peripherally bind to the surface of spermatozoa and exhibit a 
range of ligand-binding properties (Topfer-Petersen et al., 2005). HSP-7 is the only spermadhesin molecule isolated from equine seminal plasma and is hypothesized to have a role in sperm-oocyte binding (Reinert et al., 1996).

Independent of age, fertility and breed, the localization of HSP-7 on equine spermatozoa was observed through indirect immunoflourescence. It is documented that the localization of HSP-7 is restricted to the equatorial region (Reinert et al., 1996) however, in this study it was observed that HSP-7 is not restricted to the equatorial segment but is also present over the midpiece region. In contrast, a different immunofluorescent pattern has been described in the boar, where localization is solely over the acrosomal cap (Sanz et al., 1992a). Even though AWN and HSP-7 share 98\% sequence similarity (Calvete et al., 1994a), the difference in localization strongly suggests that these proteins have different roles in the molecular events of reproduction.

When assessing neat spermatozoa collected during the breeding season, equatorial segment binding was the primary site of localization and during the non-breeding season, many cells displayed a combination of equatorial segment and midpiece labeling. This binding pattern may be due to the lack of replenishment of seminal plasma through repeated ejaculations, as seen during the breeding season. Therefore, HSP-7 may develop non-specific binding for epitopes on the midpiece region. Since the equatorial segment has been defined as the zona pellucida binding domain (Senger, 2005), it is plausible that HSP-7 has zona pellucida binding properties. Additional 
research needs to be conducted to determine the significance of HSP-7 localization to the midpiece. HSP-7 may have specificity to the mitochondria that are found in high number within the midpiece region. If this is the case, HSP-7 may also participate in the development of energy reserves.

Morphologically abnormal spermatozoa displayed the same immunofluorescent pattern as morphologically normal spermatozoa. It does not appear that HSP-7 is specific to morphologically normal cells but since approximately $30 \%$ of the cells within a given population were void of immunofluorescence, it is possible that HSP-7 has molecular selectivity. Previous literature states that HSP-7 is observed on A-spermatogonia (Hoshiba and Sinowatz, 1998; Reinert et al., 1997). Therefore, spermatozoa may contain HSP-7 below the lipid bilayer. Ethanol permeabilized spermatozoa displayed HSP-7 immunofluorescence on the lower third of the sperm head and the length of the principal piece, without equatorial segment binding. Not all permeabilized cells displayed fluorescence, indicating that HSP-7 has cell specificity that is determined early in spermatogenesis. The reason for this localization pattern is unknown and was not explored further in this study.

Immunoflourescence of capacitated spermatozoa was present over the apical third of the acrosome, equatorial segment and midpiece. The acrosomal cap labeling pattern was not consistent with the pattern seen on boar spermatozoa because in the horse, it was not ubiquitous across the 
acrosomal cap. Instead, it is lightly dappled across the apical third of the sperm head. During immunoflourescent studies of capacitated cells, no attempt was made to differentiate between acrosome reacted/capacitated and non-capacitated cells. Therefore, flow cytometric studies isolating capacitated and non-capacitated cells followed by immunoflourescence would be ideal to differentiate the immunofluorescent pattern of these two populations.

Western blot analysis of total sperm protein yielded a single protein band at an approximate molecular weight (MW) of $30 \mathrm{kDa}$. This protein band is slightly larger than what previous studies have identified at a MW of $16 \mathrm{kDA}$ (Calvete et al., 1994a). This variation may be due to the extraction protocol or more likely, the formation of HSP-7 dimers within the extraction supernatant. When protein abundance was compared between stallions, it was evident that HSP-7 abundance varies between stallions. There may be a statistical relationship between stallions of high fertility and stallions of incredibly low fertility such as $30 \%$ conception or lower. This relationship was not evaluated in this study because none of the stallions used in this experiment had a conception rate in this category. Therefore no statistical significance was observed between fertile and subfertile stallions in respect to protein concentration $(P$-value $>0.05)$.

Relative HSP-7 abundance was also evaluated from semen collected during three time intervals: December, March and May. These three time frames were chosen to represent the non-breeding season, mid-breeding 
season and progression toward the end of the breeding season. The reproductive activity of horses is highly influenced by the photoperiod with seasonal changes including an alteration in testicular weight and size, sperm production and testicular secretions (La Falci et al., 2002; McKinnon and Voss, 1992; Petrunkina et al., 2000).

This study indicated that fertile stallions displayed an increase in HSP7 abundance as the breeding season approached, with a peak concentration occurring during the month of March. Sub-fertile stallions displayed only a mild increase in HSP-7 abundance when compared to fertile stallions. While this was a visual relationship, there is no statistical significance between protein abundance and breeding season.

Unlike the boar, where AWN abundance decreases between neat and post capacitated sperm samples (Dostalova et al., 1994b), equine HSP-7 abundance increases. A significant increase in HSP-7 was observed in postcapacitated sperm samples when compared to HSP-7 abundance of neat spermatozoa $(P<0.05)$. This finding is consistent with the proposed physiological role of HSP-7 in primary zona pellucida binding since zona pellucida binding proteins are exposed with capacitation. Our results do not preclude a role for HSP-7 in capacitation but its localization and distribution leads to the hypothesis that HSP-7 participates more significantly in zona pellucida binding than previously determined. Literature has stated that HSP7 contains heparin-binding domains and may play a minor role in capacitation 
but at a level which was not determined through the approaches used in this study (Rodriquez-Martinez et al., 1998; Calvete et al., 1994a). The immunofluorescent patterns observed are likely due to protein translocation within the plasma membrane during capacitation due to the increase in membrane fluidity that occurs during the capacitation process.

The interaction between male and female gametes involves numerous adhesion molecules. With HSP-7 displaying zona pellucida binding properties, the presence or absence of HSP-7 in the subpopulation of spermatozoa that fertilize an oocyte needs be evaluated. A study of this kind poses many challenges due to the inability to consistently conduct successful in vitro fertilization in the equine specie. The inability to flush oocytes from inseminated mares prior to complete engulfment of the spermatozoon has created a challenge in evaluating spermatozoa that are able to bind an oocyte in vivo. With these challenges in mind, sperm-oocyte binding assays using equine spermatozoa with bovine oocytes have proven to be a valuable alternative (Calvete et al., 1994a; Sinowatz et al., 2003).

The implementation of transvaginal ultrasound guided follicular aspiration yielded six equine oocytes ( $10 \%$ success rate). It is hypothesized that the lack of an aspiration pump and double lumen aspiration needles had led to the reduced recovery rate. In place of an aspiration pump, a 60cc syringe was used to apply negative pressure within the lumen of the preovulatory follicle. One hundred fifty millimeters of mercury $(150 \mathrm{mmHg})$ is 
generally used. A single lumen aspiration needle was used in place of a double lumen needle because manufacturers no longer make $60 \mathrm{~cm}$ length double lumen aspiration needles that are required in the equine specie. Single lumen aspiration needles do not allow the pre-ovulatory follicles to be flushed with follicular fluid between aspiration attempts. Even though an oocyte within a $40 \mathrm{~mm}$ pre-ovulatory follicle should have weak attachment to the follicular wall and cumulus mass, the attachment may have been strong enough to withstand the pressure applied with a 60cc syringe. Repeated flushing of the pre-ovulatory follicle with follicular fluid could have released the attachment of the cumulus mass and allowed the oocyte to be suspended and aspirated.

The oocytes obtained from equine transvaginal follicular aspiration and from a local bovine abattoir were vitrified using cryovials equipped with a nylon cryoloop. The challenge with oocyte vitrification is that oocytes are extremely vulnerable to cryoprotectants and are easily affected by the fast cooling and warming rates (Mavrides and Morroll, 2002). The aim of this study was to repeat a vitrification procedure by Maclellan and coworkers (2002) where high success rates were reported. In this study, thawed oocytes were used for sperm-oocyte binding assays using equine spermatozoa and bovine oocytes. After incubation and processing of the sperm-oocyte complexes for immunofluorescence, spermatozoa were no longer bound to the zona pellucida. Either longer incubation times should have been used to assure a strong attachment of spermatozoa to the oocytes or a different protocol 
should have been attempted to preserve the attachment of spermatozoa to the oocytes. Oocytes that were processed for immunofluorescence, displayed a ubiquitous labeling pattern of HPS-7 over the entire oocyte surface.

Reinert et al. has documented that HSP-7 is bound to the surface of neat and capacitated spermatozoa at the equatorial segment and below the lipid bilayer (1997). The domain that overlies the equatorial segment initiates in vivo fusion of the sperm plasma membrane with the oolemma, thus HSP-7 and other proteins isolated to this region represent proteins with zona pellucida binding properties. After in vitro capacitation, HSP-7 mobilizes in part to the acrosomal cap to aid in the acrosome reaction and penetration through the zona pellucida. In addition, the increase in HSP-7 abundance seen between ejaculated and post capacitated cells further represents zona pellucida binding properties since zona binding proteins are exposed during capacitation. Through this research, a greater understanding of HSP-7 has been made, indicating that HSP-7 appears to have a different role in reproduction then previously documented. Even though HSP-7 and AWN are $98 \%$ homologous, it is not indicated that they have the same physiological role and should be evaluated individually. 


\section{REFERENCES}

1. Aarons, D., Boettger-Tong, H., Holt, G., and Poirier, G.R. (1991). Acrosome reaction induced by immunoaggregation of a proteinase inhibitor to the murine sperm head. Mol. Reprod. Dev., 30, 258-264.

2. Albarracin, J.L., Morato, R., Rojas, C., and Mogas, T. (2005). Effects of vitrification in open pulled straws on the cytology of in vitro matured prepubertal and adult bovine oocytes. Theriogenology, 63, 890-901.

3. Baumber, J., and Meyers, S. (2006). Changes in membrane lipid order with capacitation in Rhesus Macaque (Macaca mulatta) spermatozoa. J. of Andrology, 27, 578-587.

4. Bavister, BD. (1989). A consistently successful procedure for in vitro fertilization of golden hamster eggs. Gamete Research, 23, 139-158.

5. Begin, I., Bhatia, B., Baldassarre, H., Dinnyes, A., and Keefer, C. (2003). Cryopreservation of goat oocytes and in vivo derived 2- to 4-cell embryos using the cryoloop (CLV) and solid-surface vitrification (SSV) methods. Theriogenology, 59, 1839-1850.

6. Benoff, S., Hurley, I., Cooper, G.W., Mandel, F.S., Rosenfeld, D.L., and Herschlag, A. (1993). Head-specific mannose-ligand receptor expression in human spermatozoa is dependent on capacitation-associated membrane cholesterol loss. Hum. Reprod., 8, 2141-2154.

7. Boatman, E., and Bavister, D. (1984). Stimulation of rhesus monkey sperm capacitation by cyclic nucleotide mediators. J. Reprod. Fertil., 71, 357366.

8. Bork, P., and Beckmann, G. (1993). The CUB domain. A widespread module in developmentally regulated proteins. J. Mol. Biol., 231, 539-545.

9. Bruck, I., Synnestvedt, B., and Greve, T. (1997) Repeated transvaginal oocyte aspiration in unstimulated and $\mathrm{FSH}$-treated mares. Theriogenology, 47, 1157-1167. 
10. Calvete, J., Nessau, S., Mann, K., Sanz, L., Sieme, H., Klug, E., and Topfer-Petersen, E. (1994a). Isolation and Biochemical of Stallion Seminalplasma Proteins. Repro. Dom. Anim., 29, 411-426.

11. Calvete, J., Sanz L., and Topfer-Petersen, E. (1994b). Spermadhesins: Structure-Function Relationships. Assisted Reproductive Technology/Andrology, 6, 316-330.

12. Calvete, J., Mann, K., Schafer, W., Sanz, L., Reinert, M., Nessau, S., Raida, M., Topfer-Petersen, E. (1995a). Amino acid sequence of HSP-1, a major protein of stallion seminal plasma: effect of glycosylation on its heparinand gelatin-binding capabilities. Biochem. J., 310, 615-622.

13. Calvete, J., Sanz, L., Dostalova, Z., and Topfer-Petersen, E. (1995b). Spermadhesins: sperm-coating proteins involved in capacitation and zona pellucida binding. Fertilitat, 11, 35-40.

14. Calvete, J., Dostalova, Z., Sanz, L., Adermann, K., Thole, H., TopferPetersen E. (1996). Mapping of the heparin-binding domain of boar spermadhesins. FEBS, 379, 207-211.

15. Calvete, J., Ensslin, M., Mburu, J., Iborra, A., Maartinez, P., Adermann, K., Weberski, D., Sanz, L., Topfer-Petersen, E., Weitze, K.F., Einarsson, S., and Rodriguez-Martinez, H. (1997). Monoclonal antibodies against boar sperm zona pellucida-binding protein AWN-1. Characterization of a continuous antigenic determinant and immunolocalization of AWN epitopes in inseminated sows. Bio. Reprod. 57, 735-742.

16. Checura, C.M., and Seidel Jr, G.E. (2007). Effect of macromolecules in solution for vitrification of mature bovine oocytes. Theriogenology, 67, 919930.

17. Cheng, A., Le, T., Palacios, M., Bookbinder, L.H., Wassarman, P.W., Suzuki, F., and Bieil, J.D. (1994). Sperm-egg recognition in mouse: characterization of sp56, a sperm protein having specific affinity to Zp3. J. Cell Bio., 125, 867-878. 
18. Cornwall, G.A., Tulsiani, P., and Orbegin-Crist, C. (1991). Inhibition of the mouse sperm surface $\alpha$-D-Mannosidase inhibits sperm-egg binding in vitro. Bio. Reprod. 44, 913-921.

19. Coutinho da Silva, M.A., Carnevale, E.M., Maclellan, L.J., Seidel, G.E., and Squires, E.L. (2002). Effect of time on oocyte collection and site of insemination on oocyte transfer in mares. J. Anim. Sci., 80, 1275-1279.

20. Cross, N.L. (1998). Role of cholesterol in sperm capacitation. Bio. Reprod., 59, 7-11.

21. Dostalova, Z., Calvete, J., Sanz, L., Hettel, C., Riedel, F., Schoncck, C., Einspanier, R., and Topfer-Petersen, E. (1994a). Immunolocalization and quantification of acidic seminal fluid protein (aSFP) in ejaculated, swim-up and capacitated bull spermatozoa. Biol. Chem. Hoppe-Seyler, 375, 457-461.

22. Dostalova, Z., Calvete, J., Sanz, L., and Topfer-Petersen, E. (1994b). Quantitation of boar spermadhesins in accessory sex gland fluids and on the surface of epididymal, ejaculated and capacitated spermatozoa. Biochemica et Biophysica Acta, 1200, 48-54.

23. Dostalova, Z., Calvete, J., Sanz, L., and Topfer-Petersen, E. (1995). Boar spermadhesin AWN-1 oligosaccharide and zona pellucida binding characteristics. Eur. J. Biochem. 230, 329-336.

24. Einspanier, R., Einspanier, A., Wempe, F., and Scheit, K.H. (1991). Characterization of a new bioactive protein from bovine seminal fluid. Biochem. Biophys. Res. Commun., 179, 1006-1010.

25. Ekhlasi-Hundrieser, M., Gohr, K., Wagner, A., Tsolova, M., Petrunkina, A., and Topfer-Petersen, E. (2005). Spermadhesin AQN1 is a candidate receptor molecule involved in the formation of the oviductal sperm reservoir in the pig. Bio. of Reprod., 73, 536-545.

26. Ellis, D., Shadan, S., James, P., Hendersen, R., Edwardson, M., Hutchings, A., and Jones, R. (2002). Post-testicular development of a novel membrane substructure within the equatorial segment of ram, bull, boar, and goat spermatozoa as viewed by atomic force microscopy. J Struct. Bio., 138, 187-198. 
27. EnBlin, M., Calvete, J., Thole, H., Sierralta, W., Adermann, K., Sanz, L., and Topfer-Petersen, E. (1995). Identification by affinity chromatography of boar sperm membrane-associated proteins bound to immobilized porcine zona pellucida. Mapping of the phosphorylethanolamine-binding region of spermadhesin AWN. Biol. Chem., 376, 733-738.

28. Fazeli, A., Hage, W., Cheng, F., Voorhout, W., Marks, A., Bevers, M., and Colenbrander, B. (1997). Acrosome-intact boar spermatozoa initiate binding to the homologous zona pellucida in vitro. Bio. or Reprod., 56, 430438.

29. Harrison, R. (2003). Cyclic AMP signaling during mammalian sperm capacitation-still largely Terra Incognita. Reprod. Dom. Anim., 38, 102-110.

30. Hinton, B. T. (2005). Chapter 7: What does the epididymis do and how does it do it? American Society of Andrology Handbook. Retrieved July 7 , 2008, from www.andrologysociety.com

31. Hochi, S., Fujimoto, T., Choi, Y., Braun, J., and Oguri, N. (1994). Cryopreservation of equine oocytes by 2-step freezing. Theriogenology, 42 , 1084-1094.

32. Hoshiba, H., and Sinowatz, F. (1998). Immunohistochemical localization of the spermadhesin $\mathrm{AWN}-1$ in the equine male genital tract. Anat. Histol. Embryol., 27, 351-353.

33. Jonakova, V., Kraus, M., Veselsky, L., Cechova, D., Bezouska, K., and Ticha, M. (1998). Spermadhesins of the AQN and AWN families, DQH sperm surface protein and $\mathrm{HNK}$ protein in the heparin-binding fraction of boar seminal plasma. J. Reprod. and Fertility, 114, 25-34.

34. Kalab, P., Visconti, P., Lectero, P., and Kopf, S. (1994). P95, the major phosphotyrosine-containing protein in mouse spermatozoa, is a hexokinase with unique properties. J. Biol. Chem., 269, 3810-3817.

35. Kenney, R.M., Hutgen, J.P., Pierson, R. H., Witherspoon, D., and Simons, J. (1983). Clinical fertility evaluation of the stallion. J. Soc. Theriogenol., 9, 7-62. 
36. Kirchhoff, C. (1998). Molecular Characterization of Epididymal Proteins. Reviews of Reproduction, 3, 86-95.

37. Kraus, M., Ticha, M., Zeleznan, B., Peknicova, J., and Jonakova, V. (2005). Characterization of human seminal plasma proteins homologous to boar AQN spermahesin. J. Reprod. Immunol., 54, 33-46.

38. La Falci, V.N., Tortorella, H., Rodrigues, J.L., and Brandelli, A. (2002) Seasonal variation of goat seminal plasma proteins. Theriogenology, 57. 1035-1048.

39. Landim-Alvarenga, F., Graham, J., Alvarenga, M., and Squires, E. (2004). Calcium influx into equine and bovine spermatozoa during in vitro capacitation. Anim. Reprod., 1, 96-105.

40. Linford, L., McCue, M., Montavon, S., and Lasley, B.L. (1992). Long term cannulation of the ovarian vein in mares. Am. H. Vet. Res., 71, 15891593.

41. Maclellan, L.J., Lane, M., Sims, M., and Squires, E.L. (2001). Effect of sucrose or trehalose on vitrification of equine oocytes 12 or $24 \mathrm{~h}$ after the onset of maturation, evaluated after ICSI. Theriogenology, 55, 310 (abstr.).

42. Maclellan, L.J., Carnevale, E.M., Coutinho da Silva, M.A., Scoggin, C.F., Bruemmer, J.E., and Squires, E.L. (2002). Pregnancies from vitrified equine oocytes collected from super-stimulated and non-stimulated mares. Theriogenology, 58, 911-919.

43. Manaskova, P., Peknicova, J., Elzeinova, F., Ticha, M., Jonakova, V. (2007). Origin, localization and binding abilities of boar DQH sperm surface protein tested by specific monoclonal antibodies. Journal of Reproductive Immunology. 74, 103-113.

44. Mavrides, A., and Morroll, D. (2002). Cryopreservation of bovine oocytes: is cryoloop vitrification the future to preserving the female gamete? Reprod. Nutr. Dev., 42, 73-80. 
45. McKinnon, A., and Voss, J. (1992) Equine Reproduction. Blackwell Publishing, USA.

46. Meizel, S., and Turner, O. (1991). Progesterone acts at the plasma membrane of human sperm. Mol. Cell Endocrinol., 11, R1-R5.

47. Meyers, S., Overstreet, J., Liu, I., and Drobnis, E. (1995). Capacitation in vitro of stallion spermatozoa: comparison of progesterone-induced acrosome reactions in fertile and subfertile males. J of Andrology, 16, 47-53.

48. Meyers, S., Liu, I.M., Overstreet, J., Vadas, S., and Drobnis, E. (1996). Zona pellucida binding and zona-induced acrosome reactions in horse spermatozoa: comparisons between fertile and subfertile stallions. Theriogenology, 46, 1277-1288.

49. Miller, J., Macek, M.B., and Shur, D. (1992). Complementarity between sperm surface $\beta$-1,4-glactosyltransferase and egg-coat ZP3 mediates spermegg binding. Nature, 357, 589-593.

50. Morel, M. (1999). Equine Reproductive Physiology and Stallion Management. CABI Publishing, UK.

51. O'Rand, G., and Widgren, E. (1994). Identification of sperm antigen targets for immunocontraception: B-cell epitope analysis of Sp17. Repr. Fertil. Dev., 6, 289-296.

52. Parris, J.J., Susko-Parrish, J.L., and Graham, J.K. (1999) In vitro capacitation of bovine spermatozoa: role of intracellular calcium. Therio. 51 , 461-472.

53. Petrunkina, A.M., Harrison., R.P., and Topfer-Petersen, E. (2000). Only low levels of spermadhesin AWN are detectable on the surface of live ejaculated boar spermatozoa. Reprod. Fertil. Dev., 12, 361-371.

54. Pommer, C. A., Rutllant, J., and Meyers, A. S. (2003). Phosphorylation of protein tyrosine residues in fresh and cryopreserved stallion spermatozoa under capacitating conditions. Bio. Reprod., 68, 1208-1214. 
55. Purcell, S., Seidel, G., McCue, P., and Squires, E. (2007). Aspiration of oocytes from transitional, cycling, and pregnant mares. Animal Reprod. Sci., 100, 291-300.

56. Reinert, M., Calvete, J., Sanz, L., Mann, K., and Topfer-Petersen, E. (1996). Primary structure of stallion seminal plasma protein HSP-7, a zonapellucida-binding protein of the spermadhesin family. Eur. J. Biochem., 242, 636-640.

57. Reinert, M., Calvete, J., Sanz, L., and Topfer-Petersen, E. (1997) Immunohistochemical localization in the stallion genital tract, and topography on spermatozoa of seminal plasma protein SSP-7, a member of the spermadhesin protein family. Andrologia 29, 179-186.

58. Rodriquez-Martinez, H., Iborra, A., Martinez, P., and Calvete, J. (1998). Immunoelectronmicroscopic imaging of spermadhesins AWN epitopes on boar spermatozoa bound in vivo to the zona pellucida. Reprod. Fertil. Dev., 10, 491-497.

59. Sabeur, K., Ball, B. (2007). Characterization of galactose-binding proteins in equine testis and spermatozoa. Animal Reprod., 101, 74-84.

60. Sanz, L., Calvete, J., Jonakova, V., and Topfer-Petersen. (1992a). Boar spermadhesins AQN-1 and AWN are sperm-associated acrosin inhibitor acceptor proteins. FEBS Lett., 300, 63-66.

61. Sanz, L., Calvete, J.J., Schafer, W., Schmid, E.R., Amselgruber, W., Sinowatz, F., Ehrhard, M., and Topfer-Petersen, E. (1992b). The complete primary structure of the spermadhesin AWN, a zona pellucida-binding protein isolated from boar spermatozoa. FEBS Lett., 300, 213-218.

62. Senger, P.L. (2005) Pathways to Pregnancy and Parturition (Second Revised Edition). Pullman, WA.

63. Sinowatz, F., Amselgruber, W., Topfer-Petersen, E., Calvete, J., Sanz, L., and Plendl, J. (1995). Immunohistochemical localization of spermadhesin AWN in the porcine male genital tract. Cell Tissue Res, 282, 175-179. 
64. Sinowatz, F., Wessa, E., Neumuller, C., Palma, G. (2003). On the species specificity of sperm binding and sperm penetration of the zona pellucida. Reprod. of Dom. Animals, 38, 141-146.

65. Thomas, A.D., Meyers, S.A., and Ball, B.A. (2006). Capacitation-like changes in equine spermatozoa following cryopreservation. Theriogenology, $65,1531-1550$.

66. Thomas, P., and Meizel, S. (1989). Phosphatidylinositol 4,5bisphosphate hydrolysis in human sperm stimulated with follicular fluid or progesterone is dependent upon Ca2+ influx. Biochem J., 264, 539-546.

67. Tienthai, P., Suzuki, K., Pertoft, H., Kjellen, L., and RodriguezMartinez, H. (2000). Production of glycosaminoglycans by the porcine oviduct in relation to sperm storage. Reprod. Dom. Anim. 35, 167-170.

68. Topfer-Petersen, E., Ekhlasi-Hundrieser, M., Kirchhoff, C., Leeb, T., and Sieme, H. (2005). The role of stallion seminal proteins in fertilization. Animal Reprod. Sci., 89, 159-170.

69. Vandervoort, C., Tollner, T., and Overstreet, J. (1994). Separate effects of caffeine and dbcAMP on macaque sperm motility and interaction with the zona pellucida. Mol. Reprod. and Develop., 37, 299-304.

70. Visconti, P.E., Ning, X., Fornes, M.W., Alvarez, G., Stein, P., Connors, S.A., and Kopf, G.S. (1999). Cholesterol efflux-mediated signal transduction in mammalian sperm: cholesterol release signals an increased in protein tyrosine phosphorylation during mouse sperm capacitation. Dev. Biol., 214, 429-443.

71. Waberski D, Magnus F, Mendonca Ferreira F, Petrunkina A, Weitze K.F., Topfer-Petersen E. (2004). Importance of sperm-binding assays for fertility prognosis of porcine spermatozoa. Theriogenology, $63,47-484$.

72. Wistrom, A., and Meizel, S. (1993). Evidence suggesting involvement of a unique human sperm steroid receptor/Cl- channel complex in the progesterone-initiated acrosome reaction. Dev. Bio., 159, 679-690. 
73. Yanagimachi, R. (1994). Mammalian fertilization In: the physiological role of reproduction (Second Edition). Raven Press, New York, pp. 189-317. 


\section{APPENDIX A: Chemical Solutions}

\section{MODIFIED-TALP}

Component

$\underline{\mathrm{mM}}$

g/L

Dry Components:

BSA

$3.0 \mathrm{~g} / \mathrm{L}$

$\mathrm{NaHCO}_{3}$

$2.10 \mathrm{~g} / \mathrm{L}$

Concentrate (50x)

Component Stock Solution
Na Lactate (60\% syrup)
$10 \mathrm{mM}$
$4.67 \mathrm{ml} / 50 \mathrm{ml}$
Na Pyruvate
$0.1 \mathrm{mM}$
$0.028 \mathrm{~g} / \mathrm{L}$
Glucose
$5.0 \mathrm{mM}$
$2.25 \mathrm{~g} / 50 \mathrm{ml}$

1. Premix $\mathrm{CaCl}_{2} 2 \mathrm{H}_{2} \mathrm{O}$ with $\mathrm{MgCl}_{2} 6 \mathrm{H}_{2} \mathrm{O}$, add to the remaining ingredients

2. Once dissolved, add concentrate to reach a $1 \times$ solution

3. After $\mathrm{pH}$ is adjusted to 7.4 , add Bicarbonate

4. Sterile filter, equilibrate overnight at $37 \mathrm{C} / 5 \% \mathrm{CO}_{2}$ before use

TBS (Tris-buffered Saline)

Component

g/L

Tris Base

2.42

$\mathrm{NaCl}$

8.0 
1. Adjust $\mathrm{pH}$ to 7.6 with $\mathrm{HCL}$

2. To make TBS-Tween-add $1 \mathrm{ml}$ Tween-20 


\section{APPENDIX B: Literature Article}

Characterization of the Equine Spermadhesin HSP-7 Found on Stallion Spermatozoa as it Relates to Stallion Fertility and Sperm Capacitation

Melodee K. Heidmiller ${ }^{1}$ (E-mail address: mheidmiller@westernu.edu)

Daniel G. Peterson, Ph. D 1 (E-mail address: dpeterso@calpoly.edu)

William E. Plummer, Ph. D ${ }^{1}$ (E-mail address: wplummer@calpoly.edu) ${ }^{*}$ corresponding author

Phone: 1-805-756-2113

Fax: 1-805-756-5069

${ }^{1}$ Animal Science Department

California Polytechnic State University

San Luis Obispo, CA 93407

\section{Abstract}

Equine spermadhesin HSP-7 is a $14 \mathrm{kDa}$ protein isolated from stallion seminal plasma and present on the surface of spermatozoa. HSP-7 displays 
carbohydrate and zona-pellucida binding properties, but the physiological role in equine fertilization is not well defined. HSP-7 has $98 \%$ amino acid sequence homology with the well-studied boar spermadhesin, AWN. Currently, these two proteins are considered to have the same reproductive function. Immunofluorescence studies presented here show that the stallion and boar spermadhesins are localized to different segments on spermatozoa. The variation in molecular compartmentalization of spermadhesin molecules in different species suggests that these structurally related proteins could be involved in independent events of fertilization. While the variation in HSP-7 abundance was not statistically significant between fertile and subfertile stallions, capacitated spermatozoa displayed a marked increase in HSP-7 when compared to neat sperm $(P<0.05)$. These results indicate that rather than aiding in capacitation, HSP-7 is exposed with capacitation and may have a more significant role in the acrosome reaction and sperm-oocyte recognition than previously documented.

Keywords: Equine; spermadhesin; seminal plasma protein; HSP-7; capacitation

\section{Acknowledgements}

The authors would like to thank Dr. Vera Jonakova (vjon@img.cas.cz) for supplying anti-AWN antibody for this research study. Financial support was 
supplied from the Illinois Equine Industry Research and Promotion Board and the California State University Agricultural Research Initiative.

\section{Introduction}

Mammalian fertilization involves sperm capacitation, gamete recognition, and sperm binding to the ovum. These events are mediated by specific interactions between molecules located on the surface of both gametes [1]. The current evaluation of stallion fertility is assessed subjectively through semen parameters (motility, concentration and morphology) and by looking at the previous breeding records of the stallion. These parameters are restricted to the physical characteristics of spermatozoa rather than the molecular components, which may be a more accurate indicator of fertility.

Seminal plasma proteins are attached to the sperm surface during epididymal transit and participate in the fertilization capability of spermatozoa. Spermadhesins are one of the many protein families found within seminal plasma and have been identified in a variety of ungulate species including porcine, bovine and equine. Boar spermadhesins have attracted many researchers over the last decade due to their participation in capacitation. Porcine AWN is the most studied spermadhesin molecule across species and is associated with sperm capacitation and zona pellucida binding [2]. The equine homolog to boar AWN shares $98 \%$ sequence homology and is termed 
horse seminal plasma-7 (HSP-7) [2]. AWN is localized to the acrosomal cap of spermatozoa and may play a role in stabilizing the plasma membrane for capacitation. On the other hand, equatorial segment binding of HSP-7 suggests a strong role in zona pellucida binding rather than sharing AWN's role in capacitation. The similarities and differences observed between spermadhesin molecules of different species raises the question of whether spermadhesin molecules have different functional roles in reproduction.

To better understand the possible roles of equine HSP-7, we assessed the localization and abundance of HSP-7 on ejaculated (neat) and post capacitated spermatozoa. To date, the characteristics of HSP-7 between fertile and sub-fertile stallions have not been documented. With the proposed role of HSP-7 in fertilization, a variation in relative protein abundance may exist between these two populations of stallions and was a goal of this study to further identify HSP-7's functional role in reproduction.

\section{Materials and Methods}

\subsection{Chemicals and Media}

Unless otherwise stated, chemicals were obtained from Sigma Aldrich (St. Louis, MO). Primary antibody, porcine polyclonal anti-AWN was kindly donated by Dr. V. Jonakova (Czech Republic) [3]. Secondary antibody, alexa fluor 488 goat-rabbit IgG $(\mathrm{H}+\mathrm{L})$ was obtained from Invitrogen (Carlsbad, $C A)$, 
$\beta$-tubulin (H-235) and actin antibodies (sc-47778), propidium iodide (PI; sc3541) and low range protein standards (sc-2360) were purchased from Santa Cruz Biotechnology (Santa Cruz, CA). All centrifugation and incubations were conducted at room temperature unless otherwise noted. Antibodies were diluted with $1 \%$ bovine serum albumin (BSA) in tris-buffered saline (TBS) for all incubations.

\subsection{Animals}

Semen was obtained from four fertile and two sub-fertile stallions. Stallion fertility was determined by evaluating previous breeding records of each stallion. Stallions were classified as being fertile with a conception rate of greater than or equal to $60 \%$, while sub-fertile stallions were classified based on a conception rate less than $60 \%$. Four stallions were individually housed at the California Polytechnic State University Equine Center, San Luis Obispo and collected from December 2007 through June 2008. In addition, two stallions were individually housed at University of California, Davis Equine Research Laboratory (School of Veterinary Medicine) and collected during January 2008. A total of 16 ejaculates from fertile stallions and 25 ejaculates from subfertile stallions were used in this study. All horses were maintained according to Institutional Animal Care and Use Committee protocols at each university.

\subsection{Semen Collection}


Semen was collected using a phantom mare and a Missouri artificial vagina with a nylon mesh filter to allow the sperm rich fraction to enter the collection bottle. Post ejaculation sperm concentration was determined using an Equine Densimeter (Animal Reproductive Systems; Chino, CA). Immediately, the sperm rich fraction was diluted to $50 \times 10^{6}$ cells $/ \mathrm{ml}$ using $37^{\circ} \mathrm{C}$ modified-TALP [4]. Modified-TALP was prepared with Tyrode's balanced salt solution ( $\mathrm{pH} 7.4,290-300 \mathrm{mOsm})$ supplemented with $25 \mathrm{mM} \mathrm{NaHCO}_{3}$, $10 \mathrm{mM}$ sodium lactate, $0.1 \mathrm{mM}$ sodium pyruvate, $3 \mathrm{mg} / \mathrm{ml} \mathrm{BSA}$, penicillin $\mathrm{G}$ and streptomycin. Modified-TALP was made fresh the day prior to each stallion collection and incubated overnight at $37^{\circ} \mathrm{C}$ with $5 \% \mathrm{CO}_{2}$ to reach physiological temperature. Diluted semen was transported to the laboratory within 10 minutes of collection for processing.

\subsection{Sperm Processing for Percoll Centrifugation and In Vitro Capacitation}

Upon arrival in the laboratory, sperm parameters including concentration, motility and morphology were measured using a Makler counting chamber (Irvine Scientific; Santa Ana, CA) according to the manufacturer's protocol. Sperm morphology was determined according to the Society of Theriogenology guidelines [5]. Samples were subsequently processed for Percoll centrifugation and capacitation, with slight modification to the protocol described by Meyers et al. [6]. Samples were centrifuged at $400 \mathrm{xg}$ for $5 \mathrm{~min}$ to sediment debris and pellet sperm which was resuspended in $4 \mathrm{ml}$ modified-TALP. A 90\% Percoll solution was prepared by 
adding $10 x$ modified-TALP to $100 \%$ Percoll. This solution was diluted with $1 \mathrm{x}$ modified-TALP to produce $84 \%$ and $42 \%$ gradients. Two $\mathrm{ml}$ of semen solution was layered over two Percoll-TALP gradients consisting of an $84 \%$ (lower) and $42 \%$ (upper) layer. After $20 \mathrm{~min}$ of centrifugation at $400 \times \mathrm{g}$, the sperm pellet was collected and re-suspended in $4 \mathrm{ml}$ of modified-TALP to wash cells of Percoll residue. The sperm suspension was centrifuged at $300 \mathrm{xg}$ for $5 \mathrm{~min}$ and the pellet was re-suspended in $1 \mathrm{ml}$ of modified-TALP. An aliquot was processed for fixation while the remainder was prepared for capacitation by determining the concentration using a Makler counting chamber and adjusting with modified-TALP to a final concentration to $20 \times 10^{6}$ cells $/ \mathrm{ml}$. In microcentrifuge tubes, 500ul of post Percoll sperm suspension was incubated at $37^{\circ} \mathrm{C}$ and $5 \% \mathrm{CO}_{2}$ with the lids open to prime cells for capacitation. After 1 hour of incubation, the incubator was adjusted to $38.5^{\circ} \mathrm{C}$ which slowly reached peak temperature in approximately 1 hour. Total incubation was equivalent to 2 hours. A final concentration of $1 \mathrm{mM}$ of dibutyryl cyclic AMP $(\mathrm{dbcAMP})$ and $1 \mathrm{mM}$ caffeine were added to the sperm suspension and incubated for an additional $30 \mathrm{~min}$ at $38.5^{\circ} \mathrm{C}$ and $5 \% \mathrm{CO}_{2}$ to activate capacitation.

\subsection{Sperm Processing for In Vitro Acrosome Reaction}

The acrosome reaction was induced according to Meyers et al. [6]. Two aliquots were incubated for an additional $10 \mathrm{~min}$ at $38.5^{\circ} \mathrm{C}$ in $5 \% \mathrm{CO}_{2}$ with $10 \mathrm{ug} / \mathrm{ml}$ progesterone suspended in dimethyl sulfoxide. Post incubation, 
samples were centrifuged at $3000 \times \mathrm{g}$ for $1 \mathrm{~min}$, supernatant was removed and the pellet was washed in $1 \mathrm{ml}$ modified-TALP. A sperm pellet was formed by centrifugation at $3000 \mathrm{xg}$ for $3 \mathrm{~min}$ and supernatant was removed. The sperm pellet was washed twice in Dulbecco's phosphate buffered saline (DPBS) through centrifugation at $3000 \mathrm{xg}$ for $3 \mathrm{~min}$. Following centrifugation and 2 washes in DPBS at $3000 \times \mathrm{g}$ for 3 minutes, an aliquot was processed for fixation while the remainder was prepared for evaluation of the acrosome reaction.

To determine the rate of the acrosome reaction, cells were incubated with $100 \mathrm{ug} / \mathrm{ml}$ fluorescein isothiocyanate Arachis hypogaia (FITC-PSA) and 2.4mM propidium iodide $(\mathrm{PI})$ for 10 minutes, covered from light. Cells were centrifuged at $8000 \times \mathrm{g}$ for 3 minutes and the pellet was re-suspended in approximately 250ul DPBS depending on pellet size. Cells were mounted on microscope slides with a drop of Vectashield (Vector Laboratories; Burlingame, CA) and evaluated with an Axioskop 40 epifluorescent microscope (Carl Zeiss; Thornwood, NY) fitted with a dual filter set (Excitation 485/20 and 546/12 with emission 515-530 and 580-630). Differential fluorescence (FITC-PSA, green; PI, red) was used to evaluate the acrosomal integrity of each spermatozoon. The acrosomal integrity was determined on 100 cells. Sperm with bright or thin green fluorescence over the acrosomal region in conjunction with a red nucleus were scored as having an intact acrosome. Sperm lacking an acrosomal matrix or a lack of green fluorescence 
were scored as having a reacted acrosome.

\subsection{Sperm Processing for Fixation}

Aliquots of neat, post in vitro capacitated and post acrosomal reacted cells were processed for fixation. Samples were centrifuged at $3000 \mathrm{xg}$ for 4 min to remove excess media. Cells were washed twice in modified-TALP through centrifugation prior to incubation in $2 \%$ paraformaldehyde (EM grade) in DPBS for $40 \mathrm{~min}$. Samples were centrifuged at $3000 \mathrm{xg}$ for $4 \mathrm{~min}$ and washed twice with DPBS. The sperm pellet was re-suspended in DPBS at an approximate concentration of $50 \times 10^{6} \mathrm{cells} / \mathrm{ml}$ with $1 \mathrm{ul}$ of $50 \times$ penicillinstreptomycin cocktail. Samples were stored at $4^{\circ} \mathrm{C}$ in Parafilm wrapped sterile cryovials.

\subsection{Indirect Immunofluorescent Microscopy}

The topography of HSP-7 epitopes on ejaculated equine spermatozoa was conducted, according to Kraus et al. [7]. Sperm cell suspension ( $\sim 5 X$ $10^{6}$ ) was spread onto coverslips surrounded by a hydrophobic barrier (PAP Pen; Invitrogen; Carlsbad, CA). Suspension remained at ambient temperature to dry ( 20 min). An aliquot of cells were permeabilized by exposure to ethanol $\left(-20^{\circ} \mathrm{C}\right)$ for 5 minutes. Fixation was accomplished by the use of methanol $\left(-20^{\circ} \mathrm{C}\right)$ for 5 minutes. Non-permeabilized cells were only exposed to methanol. After the cells were fixed, they were washed 3 times with DPBS. Cells were incubated for 30 minutes in blocking solution (10\% BSA in DPBS) 
and thoroughly washed with DPBS. Coverslips were incubated with anti-AWN (1:5000) for 2 hours at $37^{\circ} \mathrm{C}$. Following incubation with primary antibody and 3 washes for 4 min each with DPBS, cells were incubated with Alexa Fluor 488 goat anti-rabbit $\lg G(1: 200)$ for 1 hour at $37^{\circ} \mathrm{C}$, covered from light. Coverslips were mounted on glass slides using Vectashield (Vector Laboratories;

Burlingame, CA) and viewed using the Zeiss Axioskop 40 epifluorescent microscope (Carl Zeiss; Thornwood, NY).

\subsection{Protein Extraction}

Total sperm protein from neat and post capacitated cells were isolated according to Ekhlasi-Hundrieser et al. [8]. Sperm samples ( $10^{7}$ cells) were separated from seminal plasma by centrifugation at $3000 \mathrm{xg}$ for 5 minutes at $4^{\circ} \mathrm{C}$. Seminal plasma supernatant was removed and the sperm pellet was resuspended and washed twice in modified-TALP. The final sperm pellet was re-suspended in 3 pellet volumes ( 200ul) of extraction buffer (10mM TrisHCL, $\mathrm{pH} 7.4,10 \%$ sucrose, 1mM ethlyenediaminetetraacetic acid (EDTA), 1\% sodium dodecyl sulfate (SDS), 2ul protease inhibitor) and allowed to extract on ice for 2 hours. Sperm debris was removed by centrifugation at $13000 \times \mathrm{g}$ for 20 minutes at $4^{\circ} \mathrm{C}$. Soluble protein supernatant was stored at $-20^{\circ} \mathrm{C}$ until used for SDS-PAGE. Protein content of each extract was determined using bicinchoninic acid protein assay kit (BCA kit; Pierce; Rockford, IL).

\subsection{Western Blotting}


A polyclonal antibody directed against purified $A W N$ was raised in rabbit and tested for specificity as described in Sinowatz [3, 9].

Prior to SDS-PAGE, total protein samples were thawed and vortexed. Fifty-five ug of total protein were premixed with $33 \% \mathrm{v} / \mathrm{v}$ bromophenolblue loading buffer (4X loading buffer diluted to $1 \mathrm{X}$ with glycerol and 10ul $\beta$ mercaptoethanol; 4X loading buffer: $13.3 \%$ SDS, $0.42 \mathrm{M}$ Tris, $0.013 \%$ bromophenolblue, $\mathrm{pH}$ 6.5). Samples were heated for 3 minutes at $99^{\circ} \mathrm{C}$ and subsequently cooled for 2 minutes prior to loading into each well of $12 \%$ TrisHCL precast gels (Bio Rad; Hercules, CA). Electrophoresis was performed at $40 \mathrm{~V}$ for approximately 4 hours and the gel was then blotted onto a nitrocellulose membrane (Millipore; Billerica, MA). The membrane was washed in tris-buffered saline containing $0.1 \%$ Tween 20 (TBS-T). Total protein was visualized using Ponceau S (0.1\% w/v in 5\% acetic acid) according to the manufacturer's protocol. After the membranes were visualized using a gel-doc system (Bio Rad; Hercules, CA), the membranes were stripped of antibodies for 1 hour at $50^{\circ} \mathrm{C}$ in stripping solution $(3.1 \mathrm{ml} 1 \mathrm{M}$ Tris at $\mathrm{pH} 6.7,10 \% \mathrm{SDS}, 352 \mathrm{ul} \beta \mathrm{ME}$ and $36.5 \mathrm{ml} \mathrm{H}_{2} \mathrm{O}$ ). After blocking for 2 hours with 5\% BSA in TBS-T, the membranes were washed in TBS-T and incubated with porcine anti-AWN (1:1000) overnight at $4^{\circ} \mathrm{C}$ on an orbital rotator. The nitrocellulose membrane was washed 3 times for 4 min each with TBS-T and incubated with goat anti-rabbit IgG conjugated with alkaline phosphatase (GAR IgG-AP; 1:5000) on an orbital rotator for 1 hour at room 
temperature. After 3 additional washes in TBS-T, alkaline phosphatase activity was visualized using the Immun-Star detection kit (Bio Rad; Hercules, CA) according to the manufacturer's protocol. Membranes were visualized using a chemiluminescence gel-doc system (Bio Rad; Hercules CA).

Membranes were stripped of antibodies and blocked in 5\% BSA as described and subsequently incubated with either the primary antibody actin or $\beta$ tubulin (1:5000) for two hours. Actin and $\beta$ tubulin were individually used as loading controls. Immun-Star detection kit and secondary antibody were the same as previously described. Low range protein standard was used to assess the molecular weights of the protein bands.

\subsection{Statistical Analysis:}

Data were analyzed using ANOVA and Students paired t-test. A variable or set of variables was considered significant at $P<0.05$. All statistical analyses were carried out using Minitab Release 14 statistical package and Microsoft Excel 2008 for Mac.

\section{Results}

\subsection{Indirect Immunofluorescent Microscopy}

The localization of HSP-7 on stallion spermatozoa was evaluated through indirect immuofluorescence using a polyclonal antibody produced against porcine AWN [3], which cross-reacts with HSP-7 [12s]. On neat sperm 
cells obtained during the breeding season, fluorescence was primarily restricted to the equatorial segment (Figure 1a). During the non-breeding season, fluorescence was specific to the midpiece region and the equatorial segment (Figure 1b). Mild midpiece labeling was observed on spermatozoa that were collected during the natural breeding season but this localization was inconsistent between samples. Morphologically abnormal spermatozoa labeled for HSP-7 with the same pattern as morphologically normal spermatozoa. Within each sample set, it was observed that individual spermatozoa contain varying amounts of HSP-7, while approximately $30 \%$ of the cells did not label for HSP-7.

Permeabilized cells displayed a different localization pattern from nonpermeabilized cells. Permeabilized cells exhibited HSP-7 localization on the lower half of the sperm head and ubiquitously down the midpiece and principal piece (Figure 2). Some permeabilized cells displayed an additional localization to the capitulum of the principal piece.

\subsection{In Vitro Capacitation}

Samples were evaluated through differential immunofluorescence for either an intact acrosome or for the absence of an acrosomal cap. From the samples evaluated $(n=6)$, an average of $64.6 \%$ of spermatozoa underwent the acrosomal reaction following progesterone treatment. This indicates that $64.6 \%$ of spermatozoa were capacitated after treatment with caffeine and 
dbcAMP. There was no correlation observed between fertile and subfertile stallions relative to their ability to undergo capacitation.

\subsection{Western Blot Analysis}

Western blots indicated that anti-AWN antibody recognizes a single band at $\sim 30 \mathrm{kDa}$ in size. Total sperm protein from stallions of varying fertility were evaluated for HSP-7 abundance which revealed that protein abundance varies between stallions with no significant difference observed between fertile and sub-fertile stallions. When comparing HSP-7 abundance between neat and post capacitated spermatozoa, HSP-7 abundance increased with capacitation $(P<0.05$; Figure 3$)$. This relationship was consistent across all samples evaluated, including stallions of high and low fertility. This infers that HSP-7 is exposed with capacitation rather than removed, which is documented with AWN.

\section{Discussion}

Mammalian fertilization is a complex process where complementary molecules on the surface of morphologically disparate gametes recognize each other, bind and ultimately facilitates fusion. This process involves a series of highly coordinated interactions between molecules in the gametes' natural environment and on the surface of the individual gametes. When ejaculated spermatozoa approach an oocyte, the spermatozoa must first be recognized by the oocyte prior to binding [10]. Zona pellucida binding proteins 
on the plasma membrane are exposed during capacitation in order for complementary oligosaccharide chains on the oocyte surface and carbohydrate-binding proteins on the spermatozoa to interact [9].

Spermadhesins are a family of secretory proteins expressed in the male genital tract of the boar, stallion and bull [11]. Spermadhesins have been documented to be peripherally bound to the surface of ejaculated spermatozoa and exhibit a range of ligand-binding properties. A major equine seminal plasma protein, HSP-7 belongs to this protein family and is $98 \%$ homologous to boar AWN [12]. Spermadhesin proteins, across species, share similarities and differences regarding their structure, participation in capacitation and zona pellucida binding activity.

It is documented that the localization of HSP-7 is restricted to the equatorial region of equine spermatozoa [2]. In this study, it was observed that HSP-7 is not restricted to the equatorial segment of neat spermatozoa but is also present over the midpiece region. In contrast, a different immunofluorescent pattern has been described in the boar, where localization is observed solely over the acrosomal cap [13]. Even though AWN and HSP-7 share $98 \%$ sequence similarity [12] the difference in localization strongly suggests that they have different roles in the molecular events of reproduction. Currently, reference to the role of HSP-7 in reproduction has been derived from research conducted on AWN. However, results from the present study indicate that these two proteins should be evaluated 
individually.

In this study, morphologically abnormal spermatozoa displayed the same immunofluorescent pattern as morphologically normal spermatozoa. It does not appear that HSP-7 is specific to morphologically normal cells but since approximately $30 \%$ of the cells within a given population were void of immunofluorescence, it is possible that HSP-7 has molecular selectivity. With the current method of semen evaluation, molecular abnormalities are unidentifiable. Previous literature states that HSP-7 is observed on Aspermatogonia $[2,14]$ and therefore, spermatozoa may contain HSP-7 below the lipid bilayer. Ethanol permeabilized spermatozoa displayed HSP-7 immunofluorescence on the lower third of the sperm head and the length of the principal piece, without equatorial segment binding. However, not all permeabilized cells displayed fluorescence, which may indicate that HSP-7 has cell specificity that is determined early in spermatogenesis. The purpose for this localization pattern is unknown and was not explored further in this study.

Spermatozoa were further processed for capacitation and the immunoflourescent labeling pattern was present over the top third of the acrosome, equatorial segment and midpiece. During immunoflourescent studies of capacitated cells, no attempt was made to differentiate between acrosome reacted/capacitated and non-capacitated cells. Therefore, flow cytometric studies isolating capacitated and non-capacitated cells followed by 
immunoflourescence would be ideal to differentiate the immunofluorescent pattern of these two populations.

When protein abundance was compared between stallions, it was evident that a variation exists between stallions. There may be a statistical relationship between stallions of high fertility and stallions of very low fertility, such as $30 \%$ conception or lower, but a relationship was not determined in this experiment since none of the stallions used in this experiment had a conception rate in this category. Therefore, no relationship was observed between fertile and subfertile stallions with respect to HSP-7 abundance.

Unlike the boar, where AWN abundance decreases between neat and post capacitated sperm samples [15], equine HSP-7 abundance increases. A significant increase in HSP-7 abundance was observed in post-capacitated sperm samples when compared to HSP-7 abundance of neat spermatozoa ( $P$ $<0.05)$. This finding is consistent with the proposed physiological role of HSP7 in primary zona pellucida binding since the event of capacitation is defined as exposing zona pellucida binding proteins. Our results do not preclude a role for HSP-7 in capacitation but its localization and distribution leads to the hypothesis that HSP-7 participates more in zona pellucida binding than previously determined. Literature has stated $[12,14]$ that HSP-7 contains heparin-binding domains and may play a minor role in capacitation but at a level which was not determined through the approaches used in this study. The immunofluorescent patterns observed are likely due to protein 
translocation within the plasma membrane during capacitation because of the increase in membrane fluidity that occurs during the capacitation process.

Present immunofluorescent studies have led to the hypothesis that HSP-7 is bound to the surface of neat and capacitated spermatozoa at the equatorial segment and midpiece region as well as below the lipid bilayer. The domain that overlies the equatorial segment initiates in vivo fusion of the sperm plasma membrane with the oolemma, thus HSP-7 and other proteins isolated to this region represent proteins with potential roles of zona pellucida binding. After in vitro capacitation, HSP-7 mobilizes in part to the acrosomal cap possibly to aid in the acrosome reaction and penetration through the zona pellucida. In addition, the difference in HSP-7 abundance seen between neat and post capacitated cells by western blot analysis further indicates zona pellucida binding characteristics. Through this research study, a greater understanding of HSP-7 has been achieved, indicating that HSP-7 has a different role in reproduction than previously documented. 


\section{IMAGES AND CAPTIONS}
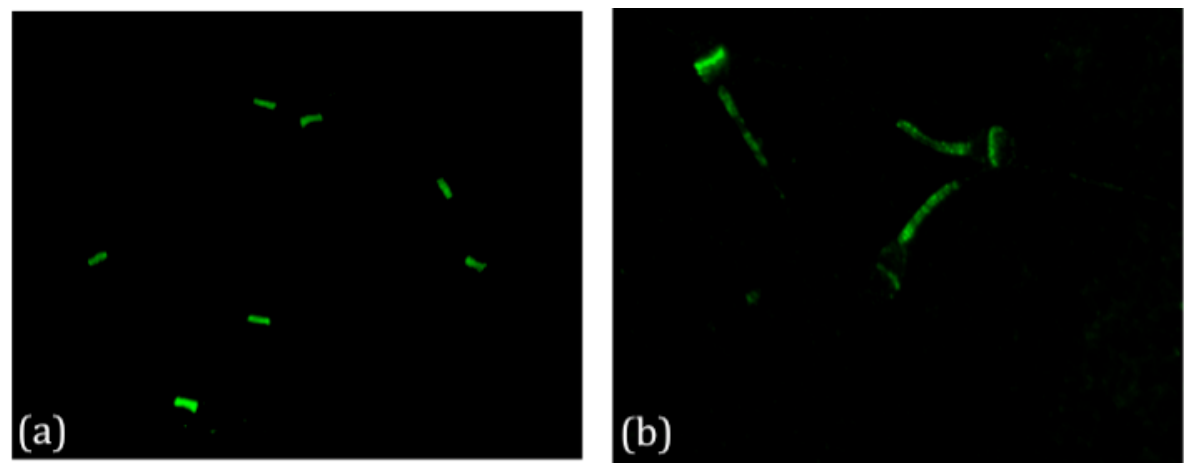

Figure 1. Indirect immunofluorescent labeling of HSP-7 on neat stallion spermatozoa during the (a) breeding and (b) non-breeding season using antiAWN polyclonal Ab. (100 X 10 magnification)

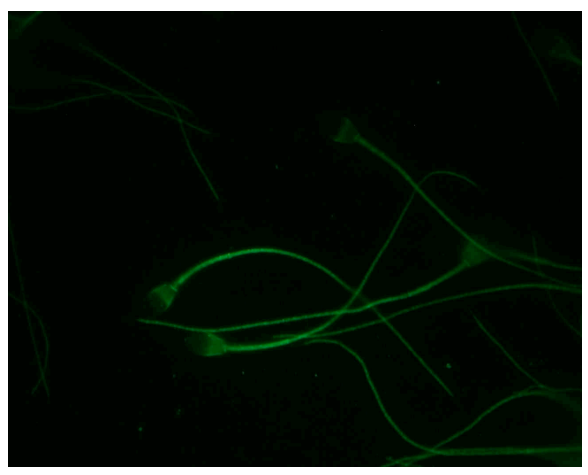

Figure 2. Labeling pattern of ethanol permeabilized stallion spermatozoa using indirect immunofluorescence and anti-AWN polyclonal antibody. (100 X 10 magnification)

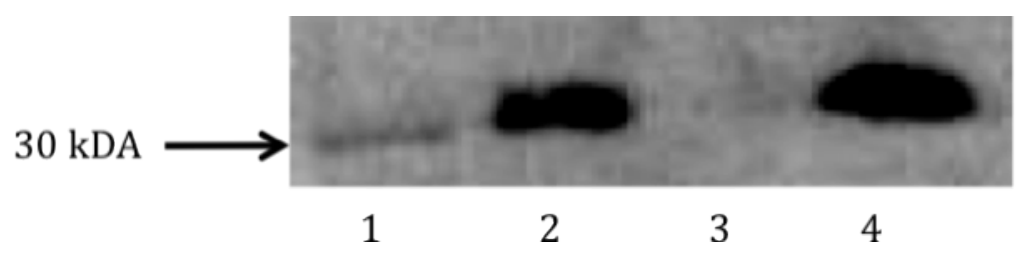

Figure 3. Western blot of detergent-extracted sperm protein from neat (lanes 1 and 3 ) and post in vitro capacitated (lanes 2 and 4) equine spermatozoa. Total protein (55ug) was loaded in each lane and subjected to $12 \%$ SDSPAGE, blotted and probed with anti-AWN polyclonal Ab. ( $p$-value $<0.05)$ 


\section{REFERENCES}

[1] R. Yanagimachi, Mammalian fertilization. In: E. Knobil and J.D. Neill, Editors, The Physiology of Reproduction ( $2^{\text {nd }}$ edition), Raven Press, New York (1994), pp. 189-317.

[2] M. Reinert, J.J. Calvete, L. Sanz, K. Mann and E. Topfer-Petersen, Primary structure of stallion seminal plasma protein HSP-7, a zona-pellucidabinding protein of the spermadhesin family, Eur J Biochem 242 (1996), pp. 636-640.

[3] V. Jonakova, M. Kraus, L. Veselsky, D. Cechova, K. Bezouska and M. Ticha, Spermadhesins of the AQN and AWN families, DQH sperm surface protein and HNK protein in the heparin-binding fraction of boar seminal plasma, J Reprod and Fertility 114 (1998), pp. 25-34.

[4] B.D. Bavister, A consistently successful procedure for in vitro fertilization of golden hamster eggs, Gamete Research 23 (1989), pp. 39-158.

[5] R. M. Kenney, J.P. Hutgen, R.H. Pierson, D. Witherspoon and J. Simons, Clinical fertility evaluation of the stallion, J Soc Theriogenol 9 (1983), pp. 7-62.

[6] S. Meyers, J. Overstreet, I. Liu and Drobnis E, Capacitation in vitro of stallion spermatozoa: comparison of progesterone-induced acrosome reactions in fertile and subfertile males, J of Andrology 16 (1995), pp. 47-53.

[7] M. Kraus, M. Ticha, B. Zeleznan, J. Peknicova and V. Jonakova, Characterization of human seminal plasma proteins homologous to boar AQN spermahesin, J Reprod. Immunol 54 (2005), pp. 33-46.

[8] M. Ekhlasi-Hundrieser, K. Gohr, A. Wagner, M. Tsolova, A. Petrunkina and E. Topfer-Petersen, Spermadhesin AQN1 is a candidate receptor molecule involved in the formation of the oviductal sperm reservoir in the pig, Bio of Reprod 73 (2005), pp. 536-545.

[9] F. Sinowatz, W. Amselgruber, E. Topfer-Petersen, J. Calvete, L Sanz and J. Plendl, Immunohistochemical localization of spermadhesin AWN in the porcine male genital tract, Cell Tissue Res 282 (1995), pp. 175-179.

[10] F. Sinowatz, E. Wessa, C. Neumuller and G. Palma, On the species specificity of sperm binding and sperm penetration of the zona pellucida, Reprod of Dom Animals 38 (2003), pp. 141-146. 
[11] P. Manaskova, J. Peknicova, F. Elzeinova, M. Ticha and V. Jonakova, Origin, localization and binding abilities of boar DQH sperm surface protein tested by specific monoclonal antibodies, Journal of Reproductive Immunology 74 (2007), pp. 103-113.

[12] J. Calvete, S. Nessau, K. Mann, L. Sanz, H. Sieme, E. Klug and E. Topfer-Petersen, Isolation and Biochemical of Stallion Seminal-plasma Proteins, Repro Dom Anim 29 (1994), pp. 411-426.

[13] L. Sanz, J. Calvete, V. Jonakova and E. Topfer-Petersen, Boar spermadhesins AQN-1 and AWN are sperm-associated acrosin inhibitor acceptor proteins, FEBS Lett 300 (1992), pp. 63-66.

[14] H. Rodriquez-Martinez, A. Iborra, P. Martinez and J. Calvete, Immunoelectronmicroscopic imaging of spermadhesins AWN epitopes on boar spermatozoa bound in vivo to the zona pellucida, Reprod Fertil Dev 10 (1998), pp. 491-497.

[15] Z. Dostalova, J. Calvete, L. Sanz and E. Topfer-Petersen, Quantitation of boar spermadhesins in accessory sex gland fluids and on the surface of epididymal, ejaculated and capacitated spermatozoa, Biochemica et Biophysica Acta 1200 (1994), pp. 48-54. 